\title{
La cultura cinematográfica en la prensa escrita Un estudio de la información, crítica y publicidad de estrenos en el diario El País
}

\author{
José Luis Sánchez Noriega \\ Universidad Complutense de Madrid
}

\section{Resumen}

Se analizan los diferentes espacios (publicidad, críticas y reportajes o entrevistas) dedicados por el periódico El País a los estrenos de películas a lo largo de un año para observar el tratamiento dado a los filmes de diferentes países y/o distribuidos por empresas transnacionales con el objetivo de descubrir si existen relaciones entre ese tratamiento mediático y los resultados de taquilla.

\begin{abstract}
This report shows us how El País newspaper deals with news related to movies' premieres along a year, trying to find all common points between media treatment and profits, focusing on countries and delivery companies involved.
\end{abstract}

Palabras claves: cine, prensa, estrenos, empresas multinacionales.

Key words: cinema, press, premiere, multinational delivery companies.

\section{CINE Y CULTURAS NACIONALES}

Como no podía ser de otro modo, detrás de este trabajo hay una preocupación que no es otra que la escandalosa hegemonía que mantiene el cine norteamericano en España, con una altísima cuota, inexistente en otros ámbitos de la creación o la cultura como la música popular, la novela, el teatro, las artes plásticas e, incluso, la ficción televisiva (que desde hace poco más de una década, y en contraste con el pasado inmediato, tiene predominio de producciones españolas). De esa constatación se deriva la pregunta sobre qué impide al cine español y europeo una mayor cuota de pantalla, para lo que hay que preguntarse, a su vez, si ello obedece a un hábito arraigado o a valores impuestos (la atracción del estrellato como criterio del espectador para elegir qué película ver) que pueden venir o no potenciados por los mensajes masivos o, por el contrario, es fruto básicamente de las estrategias publicitarias, promocionales y mediáticas utilizadas por las 
La cultura cinematográfica en la prensa escrita...

distribuidoras en los estrenos de cine norteamericano. Por ello nos planteamos un estudio que indagara en el contexto cultural-mediático de los estrenos de películas, tanto españolas como extranjeras, en nuestro país. Antes de ello, es preciso, si quiera de forma sumaria, indagar en la identidad cultural, industrial y política de los cines nacionales cuya supervivencia parece amenazada por el hegemónico.

Esta expresión ("cines nacionales"), con toda la ambigüedad que el adjetivo implica, tiene relevancia, sobre todo, a partir de los años sesenta, cuando hay una mayor toma de conciencia del imperialismo cultural norteamericano y viene a identificar los cines europeos, latinoamericanos y asiáticos en oposición al estadounidense en su vertiente más comercial, es decir, al "hollywoodiense". Frente a otros marcos de reflexión, en la teoría e historia del cine no ha aparecido en primer plano el debate sobre la interrelación estado-nación-cultura, las señas de identidad nacionales y los mecanismos que la establecen. Aunque la defensa de los "cines nacionales" busca el refuerzo de las culturas minoritarias, cinematográficamente hablando, básicamente tiene un sentido cultural de carácter anticomercial y un sentido político de signo antiimperialista. La propuesta de Guy Hennebelle (Los cinemas nacionales contra el imperialismo de Hollywood) ${ }^{1}$ viene a reivindicar los cines del Tercer Mundo y las alternativas estéticas y políticas que ofrecen a la hegemonía norteamericana y al tradicional eurocentrismo desde una consideración general del cine -y de la cultura- como instrumento de liberación social y política. Parece fuera de duda que Hollywood ha impuesto en el resto del mundo un estándar de lenguaje cinematográfico, unos modelos de géneros, una mitología de los actores y una tipología de espectador y de espectáculo que excluyen o relegan otros tratamientos audiovisuales, el documental comprometido o cualquier experimentación (en general, es cine de consumo o cine espectáculo frente al cine como expresión cultural); y también es bastante evidente que el triunfo en Hollywood (los Oscar) viene a funcionar como mecanismo de legitimación pública de la calidad de sus películas en la mayoría de los países ${ }^{2}$.

Más allá de esa problemática concreta -aunque no se puede soslayar, ya que está en el fondo de buena parte del debate- la cuestión de los cines nacionales tiene que ver, al menos, con

a) las culturas nacionales o el ámbito político-territorial de las naciones;

b) la lengua y el humus cultural; y

c) la "nacionalidad" jurídica de las películas.

\footnotetext{
1 Publicado en español con prólogo de Fernando E. Solanas por Fernando Torres editor, Valencia, 1977 (original en Editions du Cerf, París, 1975).

${ }^{2}$ También fuera de Estados Unidos cineastas y gobernantes exhiben con éxito un óscar de la Academia y las taquillas se hacen eco de las películas premiadas. La mera candidatura de una película extranjera es considerada, en cualquier país, un éxito reseñable; quizá por ello el mimetismo de los cines nacionales hacia Hollywood llega a extremos como tomar prestado el idioma y, paradójicamente, ser excluido en la selección previa precisamente porque las películas no emplean la lengua del país, como ha sucedido en la $78^{\mathrm{a}}$ edición de los Oscar con las obras presentadas por cuatro países: Grecia, Austria, Italia y Singapur (véase El País, 30-12-2005).
} 
No está claro que los cines nacionales se identifiquen siempre con culturas nacionales o con naciones (coincidan éstas o no con Estados soberanos), al menos en cuanto hay conceptos más globalizadores, como el de "cines árabes" o "cine europeo", o en cuanto muchos países carecen de la masa crítica de películas para constituir un cine nacional (pensemos en Panamá, Guatemala y otros países latinoamericanos). Incluso en el caso de cinematografías con una tradición y una producción consolidadas hay que reconocer un alto grado de convencionalismo a la hora de referirse a ellas; quiero decir que, en muchas ocasiones, hablar de cine indio o de cine español o de cine argentino tiene que ver más con la "nacionalidad" jurídica o existencia legal de las películas que con su potencial para formar parte de la cultura nacional. También sucede que la nacionalidad de los directores o su origen nacional no siempre resuelve el problema: creo que Luis Buñuel es un director que hay que situar en el cine español a pesar de haber rodado muy poco en España, del mismo modo que Viridiana es una película española aunque figure como producción mexicana, y no está claro que Billy Wilder forme parte de Hollywood. En todo caso, la universalización de los temas es palpable en gran parte de las cinematografías, singularmente europeas.

Parece que la lengua ha de ser un componente determinante en la construcción de los cines nacionales, al menos en cuanto el idioma pertenece al núcleo de la identidad de los pueblos. Se da la paradoja de que la defensa de los cines nacionales y la resistencia a la colonización del cine norteamericano pasa por exigir limitaciones al número de películas y/o de copias que se estrenan dobladas al mismo tiempo que las distribuidoras de esas producciones reciben ayudas públicas para ser estrenadas en las lenguas peninsulares distintas al castellano. En todo caso, hay que relativizar el componente lingüístico debido a la generalización del doblaje, a la existencia de cines que comparten el mismo idioma -aunque presentan usos particulares de la lengua (cine en castellano en la Península y en países latinoamericanos)- y de películas en idiomas distintos al de la cultura de referencia ( $L a$ lengua de las mariposas es una película muy gallega aunque hablada en castellano). Se buscan los mercados internacionales con rodajes en inglés y crece el número de directores transterrados y emigrantes eventuales. Las raíces culturales de una película (espacio social y geográfico, tradiciones de referencia, música, obra literaria de base, etc.) pueden determinar, más aún que el idioma, la pertenencia de una película a un cine nacional y es la defensa de la identidad cultural en que se enmarcan esas raíces lo que está a la base de la defensa de los "cines nacionales".

Por último, el criterio objetivo de la sede jurídica de la productora determina la nacionalidad de una película cualquiera que sea el idioma, el lugar de rodaje, el pasaporte de los actores y técnicos o la tradición cultural en que se inscribe. Objetivamente, una película como Two Much (Fernando Trueba, 1995) es una producción española, por más que esté rodada en inglés, en Florida (EE.UU.), con la mayoría de actores estadounidenses y con una historia y un tratamiento que tiene raíces reconocidas en la comedia norteamericana. Del mismo modo que la trilogía El señor de los anillos (Peter Jackson, 2001-2003) aparece como produc- 
ción neozelandesa por más que resulta muy identificable con el cine de Hollywood. Los grandes estudios de Hollywood se han valido de empresas instrumentales para disfrazar la nacionalidad de la productora real y, así, soslayar las legislaciones europeas de "excepción cultural" y hasta acceder a subvenciones públicas de protección de los cines nacionales y/o comunitarios. No obstante, este criterio tan insatisfactorio tiene la limitación de que las comunidades incluidas en un Estado supranacional carecen de personalidad jurídica en este ámbito.

Al final, en un escenario que destaca por la universalización de los citados estándares de Hollywood, la internacionalización de las producciones y el mestizaje cultural, la defensa de los antiguamente llamados "cines nacionales" alcanza un doble sentido: por una parte, es defensa de la diversidad cultural al apostar por un cine enraizado en la cultura y lengua propias de esas cinematografías; por la otra, se trata de una labor de resistencia frente al cine de consumo o de espectáculo ocioso desde la fuerte convicción del audiovisual como medio de expresión cultural y de que la historia del cine se encuadra, junto a la de la música, la literatura o las artes plásticas, dentro de la Historia de la Cultura.

\section{CUESTIONES PREVIAS, METODOLOGÍA Y DATOS PARALELOS}

Idealmente habría que hacer un macroestudio que tuviera en cuenta el tratamiento de los estrenos en el grueso de los medios de comunicación, esto es un análisis del conjunto de los mensajes de prensa escrita, radio, televisión e internet sobre cada uno de los estrenos cinematográficos; pero ante la imposibilidad evidente hemos optado por centrarnos en un medio escrito (donde resulta más fácil el cómputo de datos), que es el diario de mayor tirada y es "diario de referencia" para el resto de la prensa. El estudio que presentamos tiene por objetivo conocer las condiciones mediáticas del estreno de las películas en España y, en concreto, las interrelaciones entre el espacio dedicado por la prensa y la recaudación de la película. Es decir, se trata de ver la relación entre la carrera comercial de un filme y la publicidad, información y crítica en el periódico. Las dificultades para un trabajo de esta naturaleza son muchas y, aunque algunas no se han podido superar ${ }^{3}$, el resultado se aproxima al objetivo propuesto.

En concreto, nuestro estudio se refiere al diario El País y al espacio (siempre considerado el texto y las imágenes como un todo) dedicado por el periódico a reportajes sobre rodajes y sobre estrenos, críticas y publicidad de las películas. Los datos que hemos tomado del periódico para cada película son

1) informaciones y todo tipo de textos sobre rodajes y participación de festivales, para lo cual hemos tenido en cuenta los números publicados dos meses antes del período considerado;

\footnotetext{
${ }^{3}$ Así, sólo algunas distribuidoras nos han facilitado el número de copias de cada estreno (Filmax, Barton Films, Manga, Lola Films, Nirvana, Sólida, TriPictures, Warner Sogefilms).
} 
2) reportajes, entrevistas y crónicas sobre el estreno o sobre premios y participación de festivales cuando el estreno era inminente (6 semanas o menos) o con la película ya en cartelera;

3) espacio dedicado a la crítica; y

4) espacio dedicado a inserciones publicitarias.

No se incluyen a) la publicidad asociada de revistas cuya portada está dedicada a un estreno, insertos de compañías de teléfonos y otras empresas que anuncian películas, regalo de entradas del propio periódico a los suscriptores y discos con la banda sonora de filmes, lo que ha sido una importante estrategia publicitaria en algunas películas como Los increíbles; $b$ ) las informaciones de premios de instituciones, excepto cuando sean simultáneas a la fase de explotación de los filmes; c) referencias aisladas en otros artículos (por ejemplo, una sección del suplemento Ciberpaís dedicada al cine de ciencia-ficción); y d) otras informaciones de cine (industria, historia, necrológicas...).

Se toma como referencia las páginas comunes a las distintas ediciones y, por tanto, se excluye la publicidad de los suplementos propios de las ediciones regionales. Hay informaciones no consideradas sobre premios a actores y directores -con películas en la cartelera- o sobre libros en que se basan las películas proyectadas o conciertos (como los de Woody Allen y su banda de jazz) aunque suponen una promoción indirecta, pero evidente, de los filmes.

En ocasiones no hay una promoción directa, como en las entrevistas con un actor en el momento en que estrena una película donde se hace un repaso a toda su carrera o aparecen otros muchos temas además de las preguntas referidas al estreno en cuestión. También hay que tener en cuenta la diferencia de valor existente entre el espacio de las páginas ordinarias del periódico y las del suplemento de los viernes Tentaciones (ahora llamado EP3).

La medición se realiza contabilizando los módulos (una página son 40 módulos de $40 \mathrm{~mm}$ de alto por $46 \mathrm{~mm}$ de ancho), que son las unidades empleadas por la publicidad y que determinan gran parte de la extensión de los textos. El cómputo lo hemos realizado respecto a películas estrenadas en Madrid en 2004, por tanto no se incluyen ni reestrenos ni exhibiciones de películas de años anteriores; tampoco aparecen datos de filmes clasificados $X$ y se prescinde de dos películas sobre las que no hay cifras de recaudación en la base de datos del ICAA: Crepúsculo rojo (Eduardo Cozarinsky), estrenada el 25 de junio y distribuida por Manga y Sucedió en España (Alex Quiroga), estrenada el 19 de noviembre ${ }^{4}$. Las cifras de recaudación se han medido hasta junio de 2005, con el fin de reflejar más

\footnotetext{
${ }^{4}$ Las diferencias con los datos del ICAA son notables, pues hemos contabilizado 421 películas mientras los datos oficiales indican un total de 1782. Las discrepancias son mucho menores a la hora de la recaudación, para la que Cultura indica un global de 691,00 millones de euros mientras nuestros datos contabilizan 674,40 .
} 
fielmente la vida comercial de los títulos. La publicidad en primera página se computa cuatro veces la interior; no se tiene en cuenta si se trata de página par o impar y otros aspectos (lugar preferente, color) que sí tienen un costo publicitario. Se consideran las películas por la nacionalidad del país con producción mayoritaria y no se tienen en cuenta los otros países.

La tabla elaborada (véase el Anexo documental) con la totalidad de estrenos contiene las siguientes columnas o entradas:
a) fecha de estreno
b) título de la película
c) director
d) nacionalidad
e) distribuidora
f) derechos de antena de Canal Plus
$g$ ) informaciones de rodaje o festival
h) informaciones de estreno
i) crítica cinematográfica
J) publicidad
k) número de copias
1) recaudación

a las que se añaden las variables combinatorias $m$ ) suma de las columnas $\mathrm{g}+\mathrm{h}+\mathrm{i} ; n)$ suma de las columnas $\mathrm{g}+\mathrm{h}+\mathrm{i}+\mathrm{j} ;$ y 0 ) diferencia entre j y $\mathrm{m}$.

Antes de analizar los resultados de nuestro estudio conviene tener en cuenta otros datos como los oficiales del Instituto de la Cinematografía y de las Artes Audiovisuales (Ministerio de Educación, Cultura y Deporte) y los de la federación de productores. El informe del ICAA tiene la particularidad de formar parte de una serie de periodicidad anual donde vienen repitiéndose las mismas tendencias. Habría que corregir algunos datos de ese informe, tanto porque no tiene en cuenta el porcentaje de cada productora y/o de cada país en una película (Luna de Avellaneda es citada como española cuando se trata de una coproducción de España y Argentina, con el $54 \%$ y el $46 \%$ respectivamente) como, según se ha comentado más arriba, por la nacionalidad atribuida en algunos casos donde el capital norteamericano está oculto tras compañías instrumentales radicadas en países comunitarios y en terceros países (Harry Potter y el prisionero de Azkaban es oficialmente una película británica y El señor de los anillos: el retorno del rey una producción neozelandesa). 
En concreto hay que subrayar las siguientes:

- La fuerte penetración del cine norteamericano en el mercado español, con una cuota de pantalla de casi el 70 por ciento para una exhibición de menos del $40 \%$ de las películas. Es decir, que a) se ven más películas norteamericanas (707 en 2004) que de cualquier otro país y se ven el doble de películas norteamericanas que de españolas (352); y $b$ ) las películas norteamericanas se ven más que las del resto de los países; así la recaudación media es de 681.717 euros frente a los 263.641 de una española o los 202.930 de las producciones de la Unión Europea. Dicho a la inversa: para su exigua cuota del $13,43 \%$ de taquilla España necesita estrenar 352 títulos y el resto de Europa 574 para una taquilla similar ${ }^{5}$.

- La distribución es un sector fuertemente concentrado, ya que sólo cinco empresas obtienen el $78 \%$ de la taquilla (sólo tres se llevan el $56 \%$ ). Esas empresas tienen fuertes vinculaciones o son filiales de los grandes estudios norteamericanos. Por orden de recaudación son Walt Disney -que funciona también con el sello Buena Vista- Warner Sogefilms, que es la alianza de la filial de Warner Bros y de la división de cine del grupo Prisa ${ }^{6}$, United Internacional Pictures (UIP), que distribuye en España las producciones de Paramount, Universal y DreamWorks ${ }^{7}$, e Hispano Fox Film, filial de 20th Century Fox ${ }^{8}$.

\section{En el caso del cine español hay que subrayar:}

- el oligopolio en la exhibición, ya que las diez primeras películas se llevan casi el 60 por ciento de la taquilla (54.905.429 euros) y, por tanto, queda para las 342 restantes un 40 por ciento;

\footnotetext{
${ }^{5}$ Datos muy similares sobre la penetración del cine norteamericano observamos en Portugal, donde, según el ICAM (Instituto do Cinema, Audiovisual e Multimedia) (Ministério da Cultura) en 2004 se exhibieron 120 películas de Estados Unidos (173 si tenemos en cuenta las coproducciones), es decir, un $40,4 \%(58,2 \%)$ del total, que consiguieron una cuota de pantalla del $75,6 \%$ (93 $\%$ considerando todos los títulos con participación norteamericana). Las 21 películas del cine portugués obtienen en su país una exigua cuota del 1,3\%.

${ }^{6}$ La compañía Warner Sogefilms es, en realidad, una alianza al 50 por ciento de dos empresas: la filial Warner Bros., que ha distribuido la mayoría de los títulos (17 películas, entre ellas las españolas La mala educación y Atún y chocolate) y la filial de Sogecable, que ha distribuido Héctor, Mar adentro, Horas de luz, Crimen Ferpecto y El asombroso mundo de Borjamari y Pocholo.

${ }^{7}$ En diciembre de 2005 la compañía Dreamworks fue comprada por el estudio Paramount (Viacom) por 1600 millones de dólares. Dreamworks había sido fundado hace sólo once años por Steven Spielberg, Jeffrey Katzenberg y David Geffen y produjo unas 60 películas, aunque continuará como marca dentro de Viacom.

${ }^{8}$ La concentración de la distribución es aún mayor en Portugal donde sólo una empresa acapara la mitad de los espectadores (Lusomundo Audiovisuais con el 51,35\%) y entre las tres primeras distribuyen las películas que son vistas por 85 de cada 100 espectadores.
} 
- el oligopolio en el área de la producción donde sólo cuatro empresas (Sogecine, Himenóptero, Estudios Picasso y Castelao) recaudan el 71 por ciento del total de ingresos;

- la totalidad de los ingresos de cine español, que ha exhibido 352 títulos, es superado en ocho millones por sólo cinco películas extranjeras, todas ellas distribuidas por multinacionales vinculadas a los grandes estudios: Shrek 2, Troya, El último samurai, Los increíbles y Harry Potter y el prisionero de Azkabán $^{9}$; y

- en todo el año cinematográfico, de los tres centenares y medio de producciones españolas sólo 17 películas vienen a superar el millón de euros de taquilla; y son 27 las que superan los 0,6 millones, cifra considerada mínima para cubrir costes según los productores (El País, 21-09-2004).

Mejor que otras posteriores, la edición 2002 del informe de la Federación de Asociaciones de Productores Audiovisuales Españoles señala algunas perspectivas importantes:

FAPAE plantea una serie de medidas a fin de que se haga viable una competencia leal en la exhibición y distribución: un mínimo de ocupación en las salas para que las películas no puedan ser desalojadas, el establecimiento de una cuota de distribución y de una cuota de doblaje, etc. Se suceden diversas reuniones con distribuidores y exhibidores así como una reunión con el Servicio de Defensa de la Competencia en relación con este asunto.

Se mantienen igualmente conversaciones con la Dirección General del ICAA junto con FEDICINE (Federación de Distribuidores Cinematográficos) y FEECE (Federación de Entidades y Empresas de Cine de España), para discutir algunas posibilidades como la reducción del número de películas que se estrenan al año, eliminar el estreno de tvmovies en salas, establecer un número máximo de copias por película en el estreno e incentivar la permanencia en salas de las películas españolas mejorando su cómputo a efectos de la cuota de pantalla. Lo que FAPAE transmite al ICAA es la preocupación del cine español ante lo que considera una evidente práctica abusiva en contra de la libre competencia cometida con la distribución para su estreno en salas de películas no comunitarias que han ocupado durante dos meses alrededor de mil pantallas, desalojando a películas españolas y europeas de salas en las que estaban haciendo una buena recaudación. A este respecto, Eduardo Campoy, convoca una rueda de prensa el 29 de enero donde se alude al incumplimiento del Convenido FEDICINE, FEECE y FAPAE firmado en 2001 y reclamando todas las medidas anteriormente mencionadas.

\footnotetext{
${ }^{9}$ El primero de estos títulos, Shrek, bate el récord histórico en el primer fin de semana con una taquilla de 6,12 millones de euros.
} 
La conflictividad del sector ha llevado a la creación, en julio de 2004, de una asociación de distribuidores independientes españoles para hacer frente a las multinacionales, sobre todo a la hora de vender títulos a las televisiones ("Distribuidoras españolas se unen contra el monopolio de EE.UU." titulaba El País del 9 de julio). La DICA (Distribuidores Independientes Cinematográficos Asociados) reúne a DeAPlaneta, Filmax, Lauren, Manga, New World Pictures y TriPictures.

\section{ANÁLISIS DE ESTRENOS DEL DIARIO EL PAÍS}

Según nuestro cómputo -que no tiene en cuenta, como queda dicho, la totalidad de la información sobre cine- de las 421 películas estrenadas en 2004 el periódico El País ha dedicado a los rodajes el equivalente a 53,4 páginas para 67 películas; 213 páginas de información sobre los estrenos, compuesta básicamente de reportajes, resúmenes de ruedas de prensa y entrevistas a actores y/o directores sobre 193 películas; y 79 páginas de crítica cinematográfica donde se han analizado 344 películas; es decir, un total equivalente a 346 páginas, inferior a las 474 páginas que suman los anuncios de estrenos de cine en ese diario durante 2004.

Más en concreto, la información sobre rodajes se ha limitado a 67 películas, una cifra muy exigua pues representa menos del $16 \%$ del total de estrenos; las películas norteamericanas superan por poco a las españolas (28 y 25), siendo casi marginal la información sobre producciones de otros países. Teniendo en cuenta que las primeras son más del doble (se estrenaron 210 norteamericanas frente a 92 españolas; $45,8 \%$ y 21,8 respectivamente) se constata un tratamiento digno, si no bueno, del cine español en ese ámbito: es decir, que frente al citado $16 \%$ de las películas sobre cuyo rodaje se informa, en el caso de las españolas la cifra sube al $27 \%$; pero no se podría esperar otra cosa en un medio dirigido a lectores españoles. Con un espacio dedicado muy similar figuran la producción de Almodóvar La mala educación y Farenheit 9/11, con la particularidad de que las informaciones de la segunda tienen lugar sobre la película ya rodada y la polémica política que suscita, en tanto de la primera es, mayoritariamente, por el interés hacia el director manchego, al margen del valor objetivo o la entidad estética de una obra aún inédita.

Mayor es la atención dedicada a los estrenos, sobre los que hay información de algún tipo en casi la mitad de las películas $(45,6 \%)$ con un promedio de poco más de una página. La crítica cinematográfica es el género periodístico dominante entre los textos de los estrenos y se ha ocupado de 344 películas ( $82 \%)$ con un máximo de media página, aunque en la mayoría de los casos (202 películas) los comentarios no superan la extensión de ocho módulos que corresponde a un recuadro dos columnas de media página. ¿Qué sucede con las 77 películas restantes sobre las que el lector no recibe un juicio crítico? Será interesante abundar en estos títulos y ver las razones de estas ausencias. En primer lugar se constata que sólo en cinco de esos 77 títulos ha habido información previa sobre el rodaje o el estreno, por lo que parece que la decisión de no publicar crítica 
La cultura cinematográfica en la prensa escrita...

alguna es coherente con el tratamiento informativo que se otorga y, en general, se trata de películas de escasa calidad o interés cultural-mediático. Respecto a la taquilla son películas menos importantes, porque la media de recaudación ha sido de 462.323 euros, menos de la tercera parte de una recaudación estándar (la media de la muestra es de 1.601.919 euros). Desde el punto de vista publicitario tampoco hay gran interés de hablar de ellas, pues menos de la mitad (32 de 77) o no han contratado ningún anuncio o era inferior a media página; llama la atención sobremanera en este grupo de películas sobre las que no se ha publicado crítica que los títulos que no han sido anunciados en el periódico tengan cifras de recaudación superiores a quienes sí han insertado anuncios, lo que nos hace pensar no en la ineficacia del diario como soporte publicitario, sino en la desvío de la inversión publicitaria hacia otros medios más populares. En efecto, un somero repaso a las 27 películas no anunciadas nos hace ver que se trata de producciones norteamericanas (18) para consumo juvenil o infantil de escasa calidad y nulo interés para la crítica o para el sector de la ciudadanía que lee la crítica. Sólo una película española (El chocolate del loro, de Ernesto Martín) ha optado por no anunciarse.

Hay 54 películas (24 de ellas españolas) que no se han anunciado en el periódico, lo que representa algo menos del $12 \%$ de la muestra; la mayoría de ellas ha tenido una exhibición muy limitada y sólo cinco superan en taquilla los cien mil euros. De éstas, La pasión de Cristo, uno de los taquillazos del año con 11,5 millones de euros, ha optado claramente por insertar publicidad en otros soportes ya que ha considerado que el target de la película no coincidía con los lectores del diario. Pero hay que llamar la atención de que el número de películas españolas sin publicidad representa una cuota importante del conjunto de ese cine -más de la cuarta parte-, lo que puede interpretarse de forma muy dispar: bien considerando la tradicional precariedad industrial que no tiene en cuenta una partida del presupuesto para la promoción, bien que películas que no se estrenarían o irían directamente a las televisiones logran exhibirse en las salas, aunque sea de forma muy modesta. La media de inserción publicitaria es el espacio equivalente a poco más de una página y sólo una minoría de 27 películas (diez españolas) se ha anunciado en el equivalente a tres páginas.

En cuanto a otros factores o circunstancias hay que señalar que sólo en dos casos en que Canal Plus no ha comprado los derechos de antena no se ha publicado una crítica; y que parecen privilegiadas las distribuidoras de cines distintos al norteamericano como Alta Films, Nirvana o Sherlock, cuyas películas son criticadas en su totalidad. Las precompras de Canal Plus (54 títulos) se refieren a adquisiciones de derechos de emisión en la fase de preproducción o antes del estreno -que, obviamente, no cubre la totalidad de las compras de la cadena de pago- y se trata de películas españolas, aunque hay algunas coproducciones (dos argentinas y cuatro de otros países: Bélgica, Italia, Francia y Estados Unidos). De este grupo de películas hay que subrayar el buen tratamiento que reciben en el diario, pues se informa sobre el rodaje en la tercera parte de ellas (frente al $16 \%$ de la muestra), el estreno recibe la atención media de 52 módulos (más de una página frente a media página del promedio en el resto) y sólo 5 carecen de crítica, 
lo cual es coherente con la inversión publicitaria que las distribuidoras hacen en el periódico, casi el doble que la media (76 módulos frente a 45). Este tratamiento favorable no le corresponde una mejor taquilla, pues la media es de 1,34 millones de euros, mientras la media global está en 1,60.

La presencia de las películas en el periódico es, por orden de importancia, debida a a) la publicidad (88\%), b) el comentario crítico (82 \%), c) la información del estreno (45,6 \%) y d) la información sobre el rodaje, en sólo el $16 \%$ de los títulos.

La relación que hay entre la suma de los textos informativos o de opinión sobre las películas y la publicidad muestra que en el caso de 136 estrenos (32,3\%) aquellos superan el espacio comercial dedicado por el periódico a anunciar las películas mientras que en $248(60 \%)$ la situación es la inversa y en el resto el espacio de los anuncios es igual al de la información. Es decir, que en los textos de El País sobre los estrenos de cine los casos en que la publicidad supera a la información son muchos más -casi el doble- que los contrarios. Obviamente no existe un patrón para juzgar si uno debe prevalecer sobre otro ni para valorar en qué medida el lector puede estar influido por uno u otro tipo de espacios o para determinar hasta qué punto la contratación publicitaria puede influir en el tratamiento periodístico de un estreno. Teniendo en cuenta la totalidad de las películas, la media de espacio redaccional es de 33 módulos sobre 40, lo que equivale a 0,82 páginas por título, mientras que la media de espacio publicitario está en 1,3 páginas. Los valores medios son 5,07 módulos de información de rodaje; 20,24 de estreno; 7,53 de crítica y 45,07 de publicidad.

Una variable importante, además de la nacionalidad de las películas aunque ligada a ella, es la empresa distribuidora de cine. En la tabla adjunta se observa, muy en primer lugar, el desvío por arriba, respecto a la media, de los valores de la distribuidora Warner Sogefilms. Ese desvío de la empresa líder en recaudación por película (con seis millones de euros: hay nada menos que ocho, de los 22 estrenos, que superan los 5 millones de euros) viene, en buena medida, determinado por el extraordinario espacio dedicado a informar sobre la película Mar adentro (hemos llegado a contabilizar más de 21 páginas de reportajes y el equivalente a 14 páginas completas de publicidad). Las informaciones sobre rodaje y estrenos de las películas de esta distribuidora triplican los valores medios y la publicidad los duplica ampliamente; salvo el espacio de la crítica -en que se ve superada por los estrenos de Columbia TriStar- lidera el resto de los valores medios considerados.

En la suma de los espacios informativos y de crítica se observa que superan la media las películas distribuidas por UIP, DeAPlaneta, Alta Films, Nirvana y Warner Sogefilms. Si tenemos en cuenta la importancia "mediática" de esos estrenos y la inversión publicitaria hay que valorar el hecho de que el periódico privilegie a dos distribuidoras pequeñas dedicadas básicamente al cine off USA, como son Nirvana y Alta Films, cuya inversión en publicidad en el diario es menor que la media ( $y$ hasta la cuarta parte en el segundo caso). Se da la circunstancia de que, con la excepción de Aurum, quienes invierten valores inferiores a la media 
en publicidad son todas distribuidoras españolas; por tanto, todas las multinacionales superan la media de inversión publicitaria (lo que también sucede en el caso de dos distribuidoras nacionales: Vértigo y Filmax).

\begin{tabular}{|l|l|l|l|l|l|l|l|}
\hline DISTRIBUIDORAS & Rodaje & Estreno & Crítica & $\begin{array}{l}\text { Valores } \\
\text { anteriores }\end{array}$ & Publicidad & $\begin{array}{l}\text { Razón } \\
\text { Publicidad } \\
\text { información }\end{array}$ & Recaudación \\
\hline Valores medios & 5,07 & 20,24 & 7,53 & 32,84 & 45,07 & 1,37 & 1601919 \\
\hline Alta Films & 18,81 & 24,66 & 10,22 & 53,69 & 10,88 & 0,20 & 708905 \\
\hline Aurum & 3,30 & 3,28 & 6,80 & 13,38 & 3,95 & 0,29 & 2470862 \\
\hline Buena Vista & 5,12 & 18,15 & 8,75 & 32,02 & 61,48 & 1,92 & 4049634 \\
\hline Columbia TriStar & 3,10 & 12,97 & 16,07 & 32,14 & 49,05 & 1,52 & 1778324 \\
\hline DeAPlaneta & 1,58 & 37,25 & 10,25 & 30,41 & 30,41 & 0,62 & 834045 \\
\hline Filmax & 4,16 & 12,83 & 5,71 & 22,70 & 50,21 & 2,21 & 1003272 \\
\hline Golem & 5,20 & 16,20 & 8,20 & 29,60 & 25,20 & 0,85 & 281232 \\
\hline Hispano Fox Film & 4,07 & 14,11 & 5,07 & 23,25 & 52,50 & 2,25 & 3097430 \\
\hline Lauren & 0,00 & 5,09 & 7,09 & 12,18 & 37,09 & 3,04 & 286234 \\
\hline Manga & 0,00 & 13,81 & 7,48 & 21,29 & 30,66 & 1,44 & 371531 \\
\hline Nirvana & 10,45 & 36,27 & 9,09 & 55,81 & 25,45 & 0,45 & 359478 \\
\hline Sherlock & 2,30 & 6,84 & 7,53 & 16,67 & 8,84 & 0,53 & 15384 \\
\hline TriPictures & 0,85 & 24,50 & 7,21 & 32,56 & 31,71 & 0,97 & 943902 \\
\hline UIP & 4,02 & 27,89 & 8,55 & 40,46 & 63,93 & 1,58 & 2606014 \\
\hline Vertigo & 4,81 & 12,93 & 9,31 & 27,05 & 50,12 & 1,85 & 454426 \\
\hline Warner Sogefilms & 16,68 & 69,95 & 10,63 & 97,26 & 112,68 & 1,15 & 6093117 \\
\hline
\end{tabular}

Elaboración propia: datos de recaudación en euros; el resto son módulos de espacio (1 página $=40$ módulos)

Razón publicidad / información: por debajo de 1 hay más información que publicidad.

Pudiera ser relevante observar la relación que hay entre el espacio redaccional y el publicitario del periódico. Como se observa en la tabla, como media por cada 45 módulos de anuncios hay casi 33 de publicidad, lo que arroja un saldo de 1,37. El valor de uno sería en el caso de que el periódico dedicara igual espacio a publicidad de estrenos que a información; los valores menores son el resultado de mayor publicidad y los superiores de mayor información. Entre 0 y la media -es decir, con un tratamiento del periódico muy favorable a la distribuidora- se encuentran varias de las distribuidoras nacionales independientes, Aurum ${ }^{10}$ y Warner

\footnotetext{
${ }^{10}$ La distribuidora Aurum surgió en Antena 3 en 1995 y ha formado parte del grupo Zeta hasta que, tras una crisis financiera de la que se recuperó parcialmente con la distribución de la trilogía El señor de los anillos, ha sido vendida al grupo canadiense Motion Picture Distribution LP en 45 millones de euros (Cine por la Red, 6 de mayo de 2004).
} 
mientras que presentan una menor rentabilidad mediática el resto de las multinacionales y las españolas Lauren, Filmax, Vértigo y Manga. En esta razón entre publicidad y textos hay diferencias notabilísimas, pues mientras que en un estreno de Alta Films por un módulo de publicidad hay cinco de información o crítica, en el caso de Lauren ha sucedido que la publicidad triplicó el espacio redaccional. Ni que decir tiene que ello no prejuzga los resultados globales de la empresa ni la rentabilidad de cada estreno...; incluso habría que comparar estos resultados con los de otros años para comprobar si se trata de una tendencia consolidada o, por el contrario, son comportamientos meramente circunstanciales.

Por lo que respecta a la crítica sobresale el buen tratamiento ${ }^{11}$ dado a los estrenos de distribuidoras de cine de autor e independiente (Alta Films, Vertigo, Nirvana, Golem y Sherlock) cuyos valores son iguales o superiores a la media; esto es más relevante en cuanto, con la excepción de Vértigo, la publicidad invertida por esas empresas en el periódico está por debajo de la media.

No hemos conseguido datos sobre el número de copias de cada título de todo el año, por lo que hemos limitado el análisis de este aspecto al primer semestre. En primer lugar la media es de unas cien copias (104), siendo el abanico muy amplio, entre las dos o tres de los estrenos más restringidos (la mayoría limitados a Madrid y Barcelona, pero también hay algunos en otras ciudades).

Por distribuidoras ${ }^{12}$, hay que señalar tres grupos:

a) Las pequeñas que no sólo distribuyen pocas películas, sino también pocas copias de cada una (empresas como Sherlock, Yedra, Festival, Karma, Sorolla, Asfalto, Civite, Indisa, etc. estrenan con menos de 10 copias); se dedican preferentemente al cine europeo.

b) Las medianas que estrenan con menos de cien copias: Golem (dos películas europeas con 13 copias); Barton (tres españolas y una francesa con 22 copias de promedio); Nirvana (4 películas iberoamericanas con 44 copias); Sólida (tres títulos con 54 copias de promedio); Vértigo (nueve películas, la mayoría europeas, con 54 copias); Alta Films (8 títulos con una media de 56 copias); Lauren (7 películas con 64 copias); DeAPlaneta (4 películas con 74 copias cada una); Manga distribuye por igual cine europeo y norteamericano (16 películas con 78 copias).

\footnotetext{
${ }^{11}$ En el caso de la crítica, aunque nuestro trabajo es cuantitativo, la cantidad equivale a crítica favorable ya que, salvo excepciones, la amplitud de la crítica es proporcional a la importancia que se le concede.

${ }^{12}$ Estas son las distribuidoras más relevantes operativas en 2004, con posterioridad han aparecido On Pictures (grupo Zeta) y Nostro Films.
} 
c) las grandes que superan el promedio de cien copias: Warner Sogefilms estrena una docena de títulos (4 españoles y el resto norteamericanos) con una media de 225 copias; Buena Vista sólo exhibe cine norteamericano (17 películas con 205 copias); Aurum sólo estrena en el semestre cuatro películas con 174 copias; Hispano Foxfilm distribuye once películas (10 norteamericanas) con 150 copias de media; UIP distribuye 18 películas norteamericanas y dos europeas (compartidas con otras distribuidoras) con 128 copias de media; TriPictures exhibe 5 películas de EE.UU. con 116 copias; y Filmax catorce películas (9 norteamericanas, 3 francesas y 2 españolas) con 110 copias.

La recaudación media se sitúa en 10.941 euros por copia; en el caso de las producciones españolas esa cifra baja a 7321 euros mientras que en las norteamericanas es de 12.108 euros por copia, lo que supone una diferencia notable. Más aún: aunque necesitaríamos datos de copias de todo el año para una comparativa rigurosa, parece que hay una relación entre la recaudación media de cada película y el número de copias tiradas, pues quienes más copias ponen en el mercado lideran a su vez esa recaudación; por orden de número de copias: Warner $(6,04$ millones por título), Buena Vista $(4,04)$, Aurum $(2,47)$ e Hispano Fox Film $(3,09)$.

Además de la señalada relación orgánica con las majors de Hollywood (Warner Sogefilms, UIP, Hispano Foxfilm, Buena Vista), de quienes son auténticas sucursales, algunas distribuidoras forman parte de grupos dedicados básicamente a la exhibición mediante la propiedad de cadenas de salas que sirve de soporte directo -y casi exclusivo- a las películas compradas, como es el caso de Cinesa (UIP) (205 pantallas y 50.000 butacas), Alta Films (139 pantallas, de las cuales 53 son en v.o. subtitulada) y Lauren (sin datos). Aunque prácticamente todas las distribuidoras editan sus títulos en DVD, algunas de ellas mantienen una actividad notable en ese sector, con la publicación de clásicos, como es el caso de Manga y DeAPlaneta. Tanta importancia tiene la producción como la distribución en el caso de Filmax y Nirvana (con Wanda como sello productor), y Alta Films, además de exhibir, participa en algunas producciones al año. En algunos casos, son empresas básicamente productoras (Lolafilms) o exhibidoras (Golem) cuya dedicación a la distribución resulta ocasional. 


\section{CONCLUSIONES E INTUICIONES}

1. El lector del diario obtiene información sobre el catálogo de estrenos -no sobre títulos concretos- gracias a la publicidad y, en menor medida, a la crítica.

2. La publicidad específica supera ampliamente el espacio redaccional del periódico dedicado a los estrenos; los comentarios críticos ocupan la sexta parte de los anuncios. No obstante, en una minoría significativa constituida por la tercera parte de los estrenos, la publicidad es menor que el espacio redaccional.

3. La información sobre rodajes está muy limitada a unos pocos títulos, la mayoría norteamericanos o españoles.

4. La cuarta parte de las películas españolas tiene estrenos "fantasmas", de muy limitada repercusión mediática.

5. Hay crítica de cine sobre el grueso de los estrenos, aunque la mayoría son comentarios no muy extensos.

6. Las películas cuyos derechos de antena han sido precomprados por Canal Plus reciben un considerable mejor tratamiento en todas las variables.

7. Warner Sogefilms y algunas distribuidoras de cine de autor e independiente obtienen un tratamiento favorable en todos los aspectos.

Probablemente se puede afirmar que

8. El número de críticas y el espacio concedido a cada una sea mayor que en otros medios escritos y, desde luego, que en otros soportes como televisión, webs y radio.

9. La distribución independiente de cine prácticamente no existe -sólo algunos francotiradores con media docena de títulos anuales- y las empresas tienen vínculos empresariales con productoras, televisiones, redes de salas o grupos multimedios.

(Recibido el 26-5-06, aceptado el 20-06-06) 


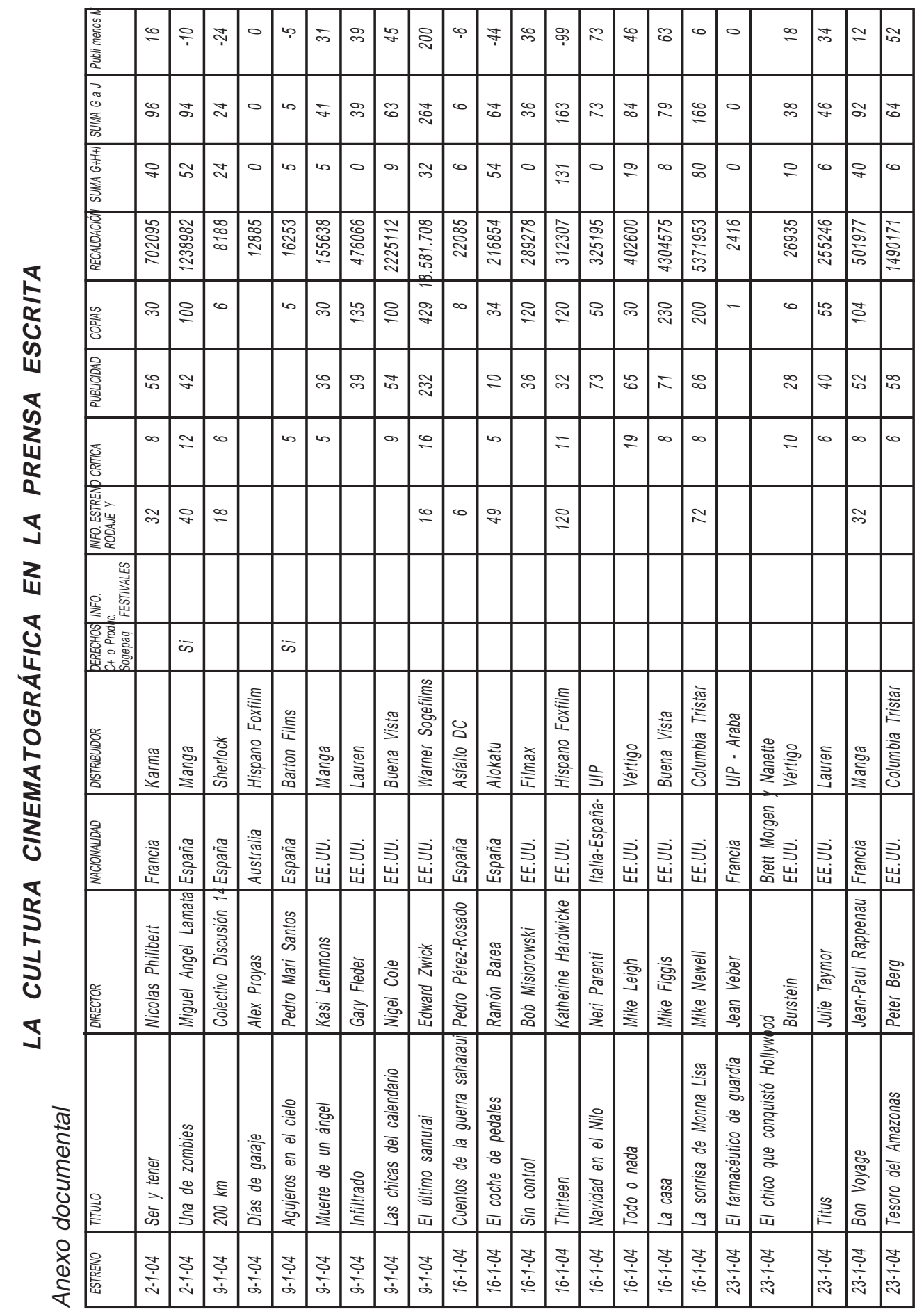




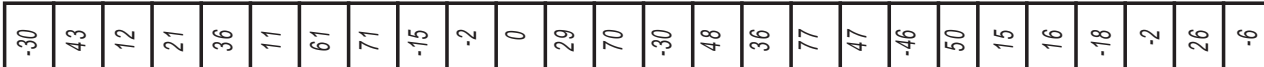
向

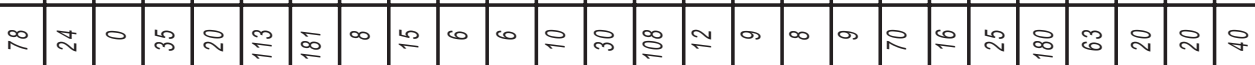

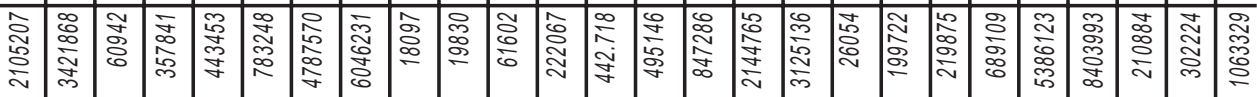

吾

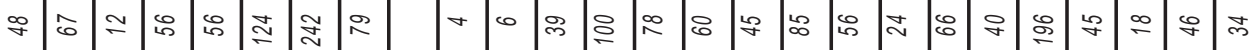

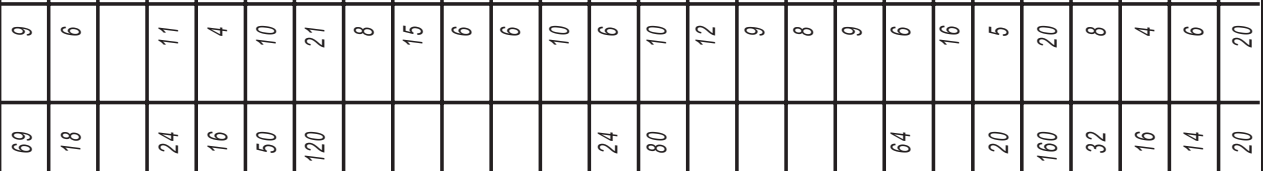

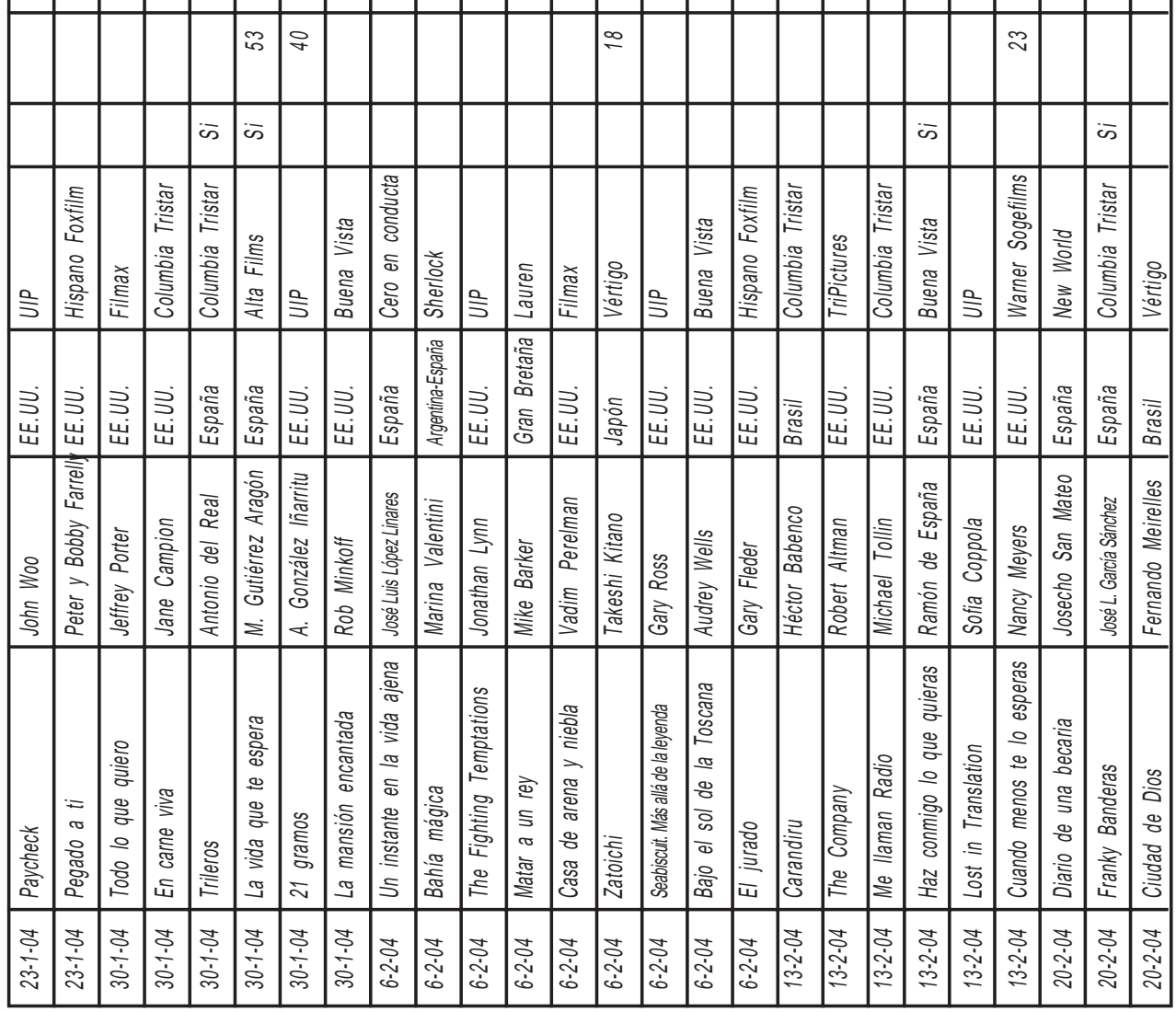




\begin{tabular}{|c|c|c|c|c|c|c|c|c|c|c|c|c|c|c|c|c|c|c|c|c|c|c|c|c|c|}
\hline 8 & is & $\underset{f}{q}$ & as & $\stackrel{\infty}{\infty}$ & $\bar{\tau}$ & $\infty$ & $\div$ & 尺 & ๗ా & 0 & ๗ & $T$ & $\div$ & 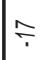 & 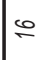 & $\bar{m}$ & 0 & co & $\stackrel{\infty}{\simeq}$ & 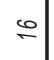 & $\sim$ & 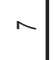 & $\therefore$ & $\infty$ & $\forall$ \\
\hline 里 & \& & $\stackrel{尺}{\sim}$ & $\approx$ & $\underset{\sim}{\Xi}$ & $\infty$ & $\infty$ & $\stackrel{\infty}{\approx}$ & is & $\cong$ & 0 & $\approx \widetilde{\infty}$ & $\neq$ & m & $\ddot{0}$ & 8 & $\stackrel{\nwarrow}{\curvearrowright}$ & $\leftarrow$ & $\infty$ & ల) & $\underset{\sim}{\sim}$ & 2 & 8 & ৪ & 寻 & $\because 8$ \\
\hline \& & is & is & os & 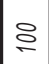 & $\approx$ & 우 & $\underset{ \pm}{I}$ & 8 & \& & 0 & 0 & os & $\approx$ & 요 & 암 & నี & $\infty$ & 0 & $\Delta$ & $\nabla$ & মे & $\stackrel{\sim}{\sim}$ & $\therefore$ & m & p \\
\hline 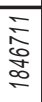 & 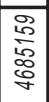 & 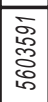 & 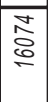 & 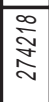 & 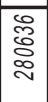 & 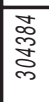 & $\begin{array}{l}8 \\
0 \\
0 \\
5 \\
5 \\
2\end{array}$ & 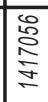 & 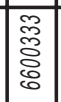 & $\frac{9}{m}$ & 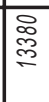 & 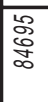 & 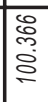 & 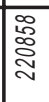 & 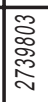 & 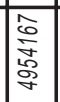 & $\stackrel{\infty}{\stackrel{\infty}{I}}$ & 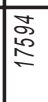 & 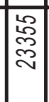 & $\begin{array}{l}\text { ळa } \\
\text { के }\end{array}$ & 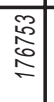 & 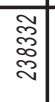 & 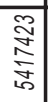 & 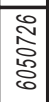 & है \\
\hline 8 & ڤ్ & $\stackrel{\sim}{\sim}$ & $\nabla$ & in & & $\stackrel{\infty}{+}$ & ণ্ণি & $\underset{Z}{ \pm}$ & & 으 & & $\nabla$ & 8 & $\cong$ & & 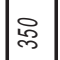 & $m$ & $\leqslant$ & o & 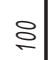 & & 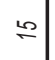 & $\underset{\sim}{\stackrel{ }{\sim}}$ & 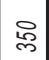 & $\approx$ \\
\hline 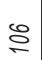 & is & $E$ & $\stackrel{\infty}{=}$ & 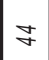 & $\bar{m}$ & $\mathscr{q}$ & 忢 & - & $\approx$ & & ๗ & $\infty$ & $\infty$ & 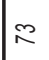 & is & $\bar{x}$ & $\infty$ & $\cong$ & $\infty$ & $\therefore$ & $\mathbb{m}$ & $\stackrel{m}{m}$ & $\infty$ & $E$ & $\approx 0$ \\
\hline$\infty$ & Lo & $\bar{\sim}$ & os & ㄱ & $\infty$ & $\infty$ & $\infty$ & $\infty$ & $\div$ & & & as & $\leqslant$ & $\infty$ & $\cong$ & $\infty$ & $\infty$ & 0 & $\infty$ & $\nabla$ & $\infty$ & $\infty$ & $\therefore$ & $\simeq$ & to \\
\hline$\approx$ & & 范 & & ৯ & $\not{\nabla}$ & চ্ল & 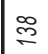 & ळે & $\underset{\sim}{\sim}$ & & & & $\cong$ & ‡ & $\stackrel{\infty}{\sim}$ & $\stackrel{\infty}{=}$ & & & $\div 2$ & & $\underset{\sim}{ \pm}$ & حి & & $\bar{\sim}$ & 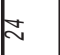 \\
\hline & & অ & & & & & & $\underset{\sim}{ \pm}$ & & & & & & & & $\infty$ & & & & & $\nabla$ & & & & \\
\hline & & & & & के & क & & & & & & & & क & & & & & & & & & & & \\
\hline 禺 & 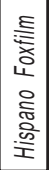 & 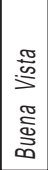 & 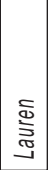 & 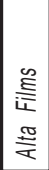 & 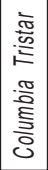 & \begin{tabular}{|l}
$\tilde{\pi}$ \\
$\stackrel{\Xi}{0}$ \\
$\stackrel{\pi}{\Sigma}$
\end{tabular} & $\stackrel{a}{5}$ & 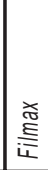 & 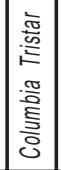 & 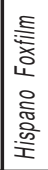 & 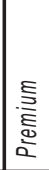 & 冚 & $\frac{\varrho}{3}$ & 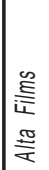 & 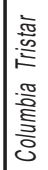 & 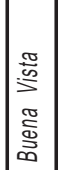 & 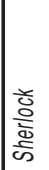 & 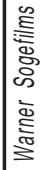 & 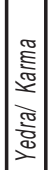 & 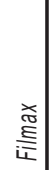 & 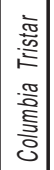 & $\begin{array}{l}E \\
\frac{1}{0} \\
\end{array}$ & $\frac{a}{5}$ & 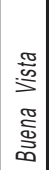 & 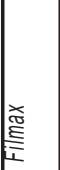 \\
\hline 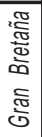 & $\begin{array}{l}\exists \\
\text { 出 }\end{array}$ & 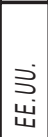 & 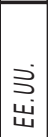 & 空 & 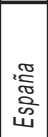 & 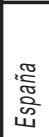 & 恿 & $\underset{\text { 出 }}{\stackrel{3}{ }}$ & 壱 & 空 & 空 & Э̧ & 空 & 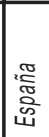 & 空 & $\underset{\text { 岃 }}{\supset}$ & 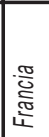 & 空 & 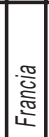 & $\underset{\mathrm{w}}{\mathrm{u}}$ & 悹 & $\mid \begin{array}{l}\frac{\pi}{3} \\
\frac{3}{\infty} \\
0\end{array}$ & 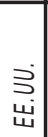 & 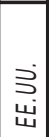 & \\
\hline 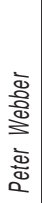 & $\begin{array}{l}\text { ज्ञ } \\
\text { 离 } \\
\text { कू }\end{array}$ & 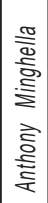 & 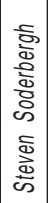 & 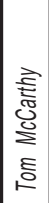 & 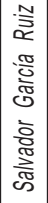 & 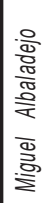 & 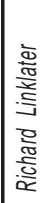 & 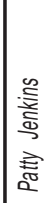 & 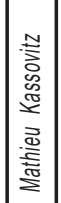 & 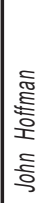 & 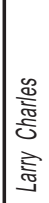 & 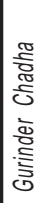 & 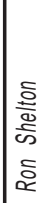 & 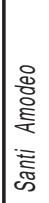 & 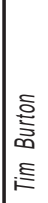 & 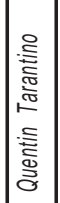 & 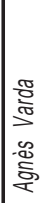 & 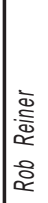 & 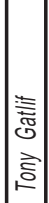 & 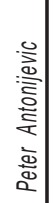 & 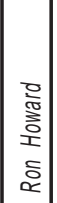 & 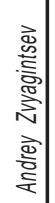 & 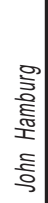 & 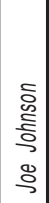 & 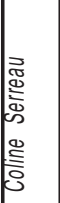 \\
\hline 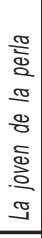 & 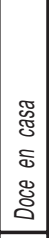 & 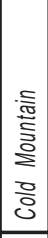 & 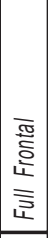 & 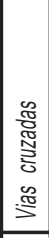 & 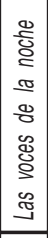 & \begin{tabular}{|l} 
잏 \\
흥 \\
J
\end{tabular} & 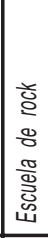 & 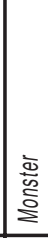 & 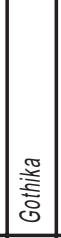 & 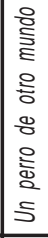 & 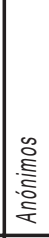 & 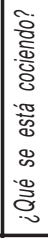 & 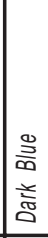 & 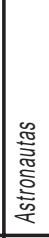 & 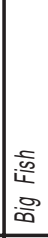 & $\begin{array}{l}- \\
\dot{\bar{s}} \\
\dot{\bar{c}} \\
\overline{\bar{c}} \\
\overline{\mathbf{3}}\end{array}$ & 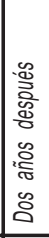 & 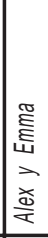 & $\mid$\begin{tabular}{l} 
क्ञ \\
\hdashline \\
के
\end{tabular} & 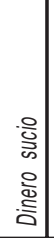 & 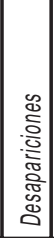 & 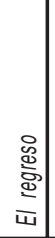 & 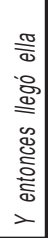 & 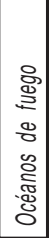 & 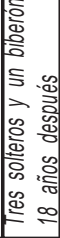 \\
\hline 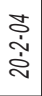 & 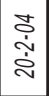 & $\begin{array}{l}\text { d } \\
\text { ஸे } \\
\text { ஸे }\end{array}$ & 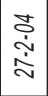 & 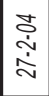 & $\begin{array}{l}\dot{d} \\
\stackrel{\sim}{\sim} \\
\stackrel{\sim}{\sim}\end{array}$ & 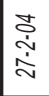 & 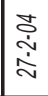 & 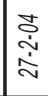 & 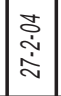 & $\begin{array}{l}\text { के } \\
\text { مे } \\
\text { in }\end{array}$ & $\begin{array}{l}\text { वे } \\
\text { 今े } \\
\text { in }\end{array}$ & 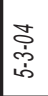 & $\begin{array}{l}\vec{b} \\
\text { 今े } \\
\text { in }\end{array}$ & 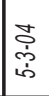 & $\begin{array}{l}\vec{c} \\
\text { के } \\
\text { in }\end{array}$ & $\begin{array}{l}\vec{b} \\
\dot{\sigma} \\
\dot{\rho} \\
\dot{\omega}\end{array}$ & 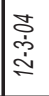 & 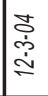 & 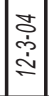 & 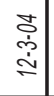 & 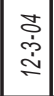 & 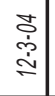 & 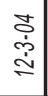 & 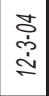 & \\
\hline
\end{tabular}




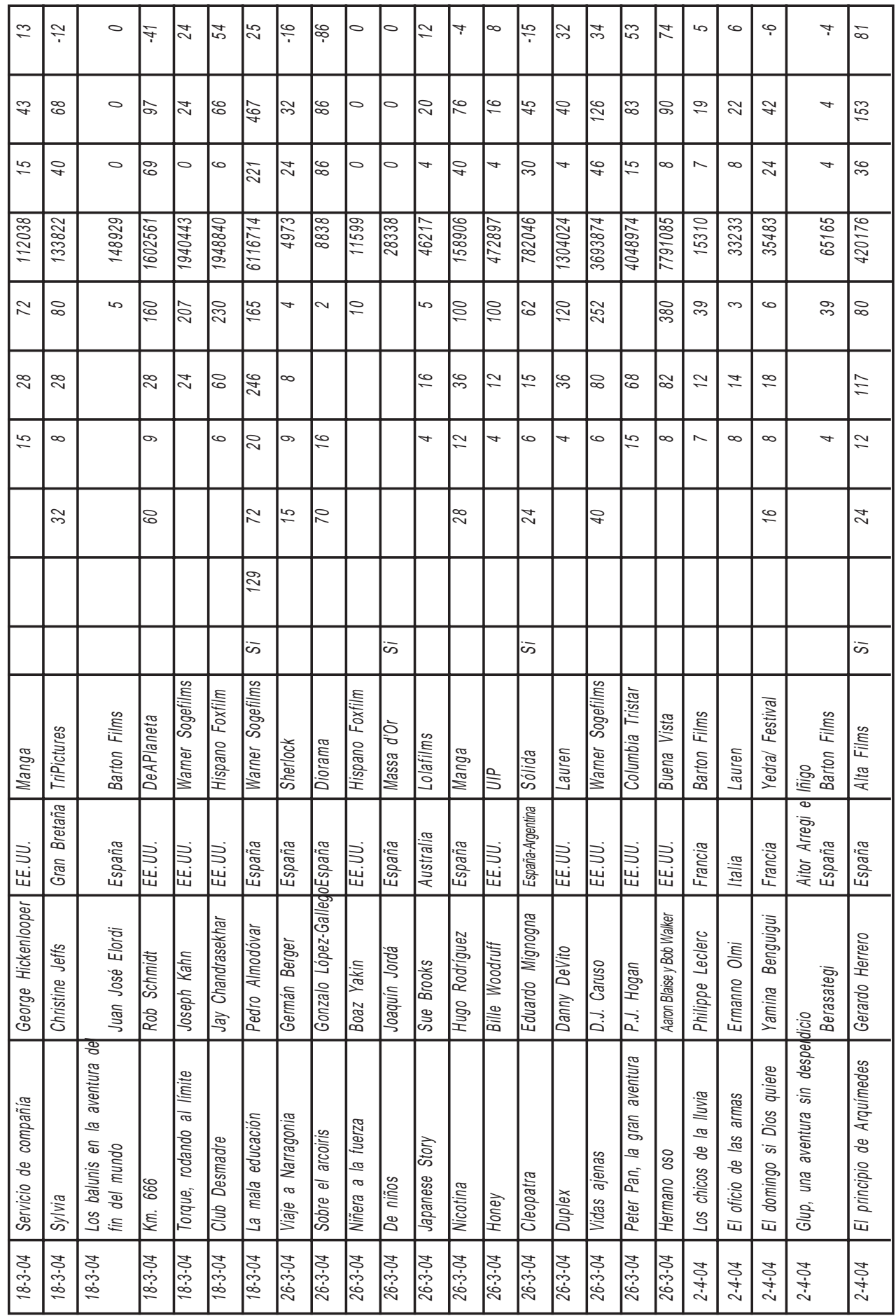




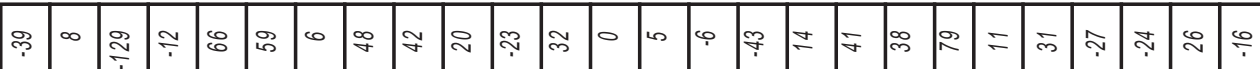

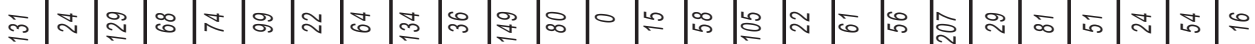

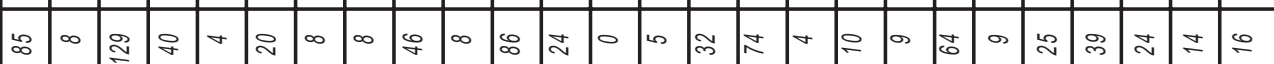

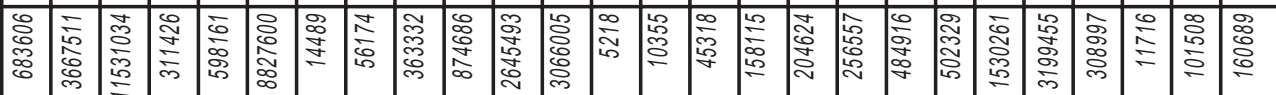
舟

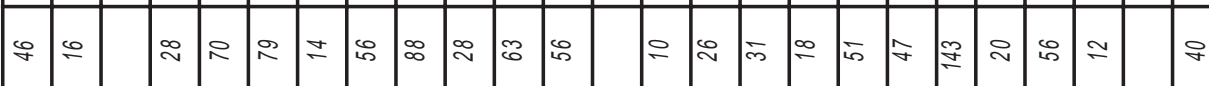

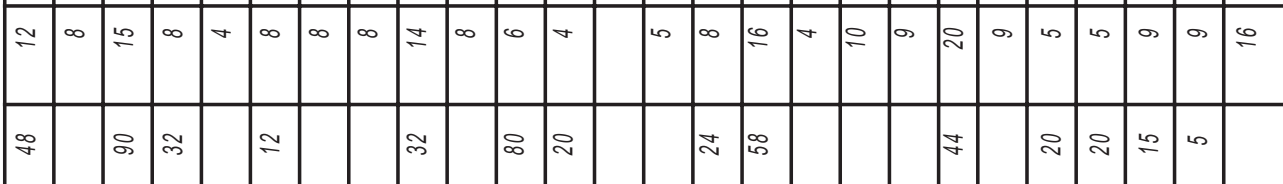

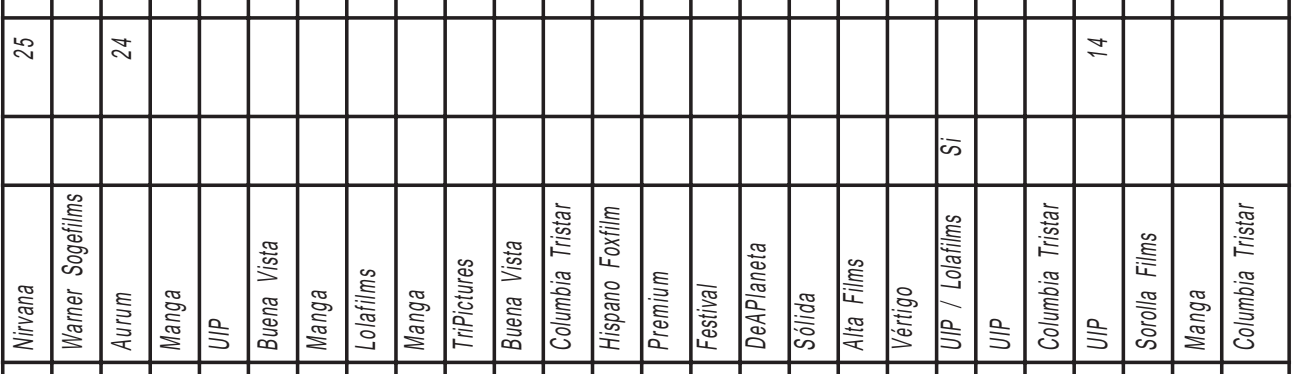

焉

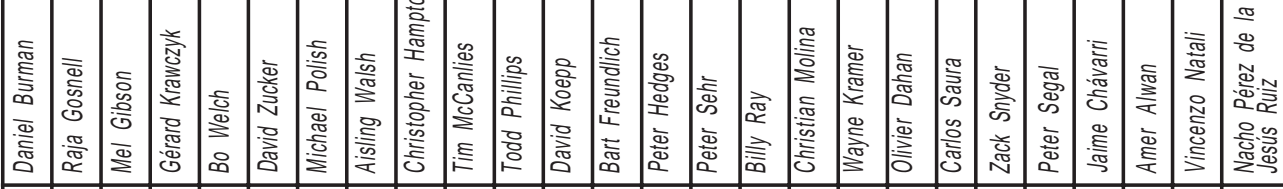

\begin{tabular}{|c|c|c|c|c|c|c|c|c|c|c|c|c|c|c|c|c|c|c|c|c|c|c|c|}
\hline 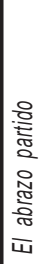 & 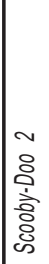 & 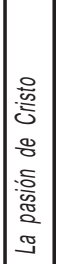 & 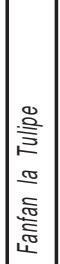 & 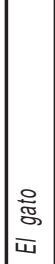 & 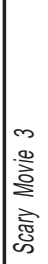 & 旁 & 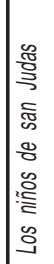 & 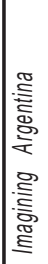 & 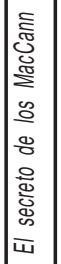 & 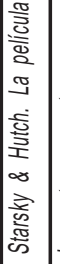 & 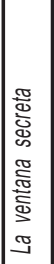 & $\mid$ & 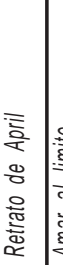 & 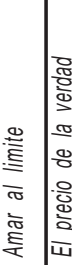 & 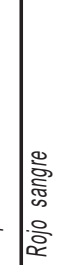 & $\mid \begin{array}{l}\bar{\Delta} \\
\bar{\partial} \\
\vdots \\
\Xi \\
\Xi\end{array}$ & 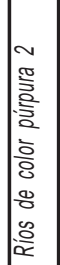 & 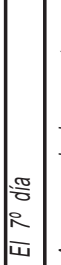 & 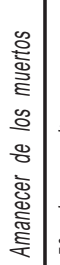 & 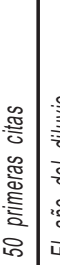 & 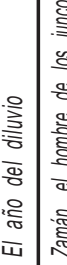 & . & 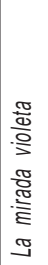 \\
\hline $\begin{array}{l}\text { to } \\
\text { d }\end{array}$ & $\begin{array}{l}\dot{a} \\
\dot{d} \\
\dot{d}\end{array}$ & 克 & 索 & 辛 & 孛 & $\begin{array}{l}\text { 孛 } \\
\text { d } \\
\text { s. }\end{array}$ & 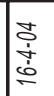 & \begin{tabular}{|l} 
\\
$\dot{0}$ \\
$\dot{d}$ \\
$\dot{b}$
\end{tabular} & $\mid \begin{array}{l}\mathbf{y} \\
\dot{y} \\
\dot{0} \\
\dot{0}\end{array}$ & $\mid$ & 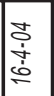 & 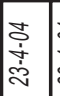 & 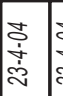 & 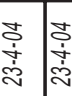 & 亲 & 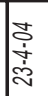 & 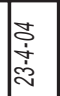 & 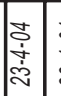 & $\begin{array}{l}+ \\
\dot{d} \\
\dot{\dot{j}} \\
\text { ஸे }\end{array}$ & 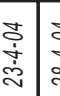 & 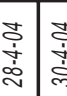 & 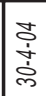 & $\begin{array}{l}\text { dे } \\
\dot{d} \\
\text { ले }\end{array}$ \\
\hline
\end{tabular}




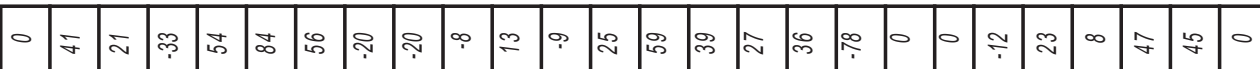

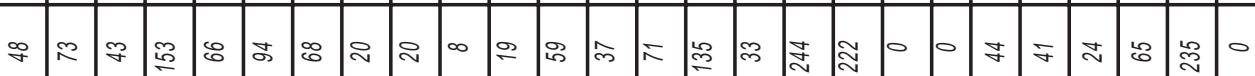

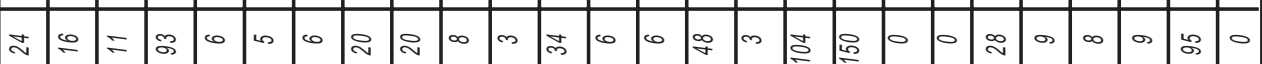

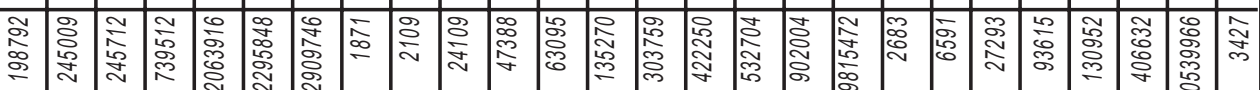

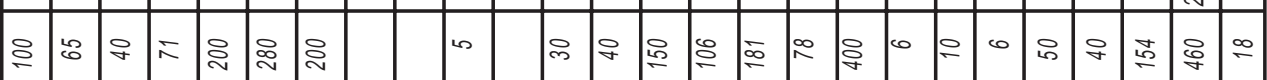

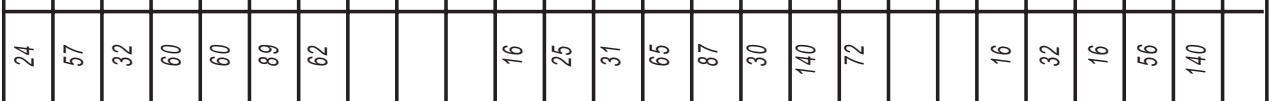

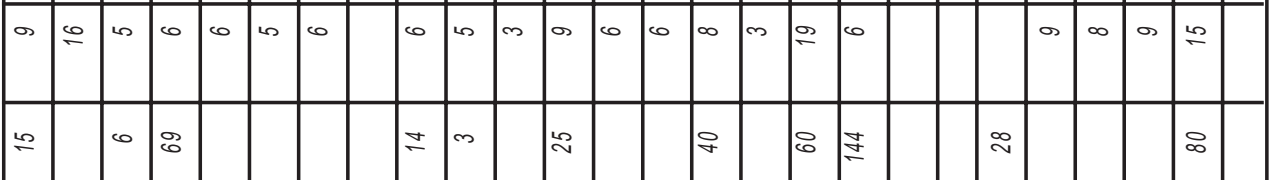

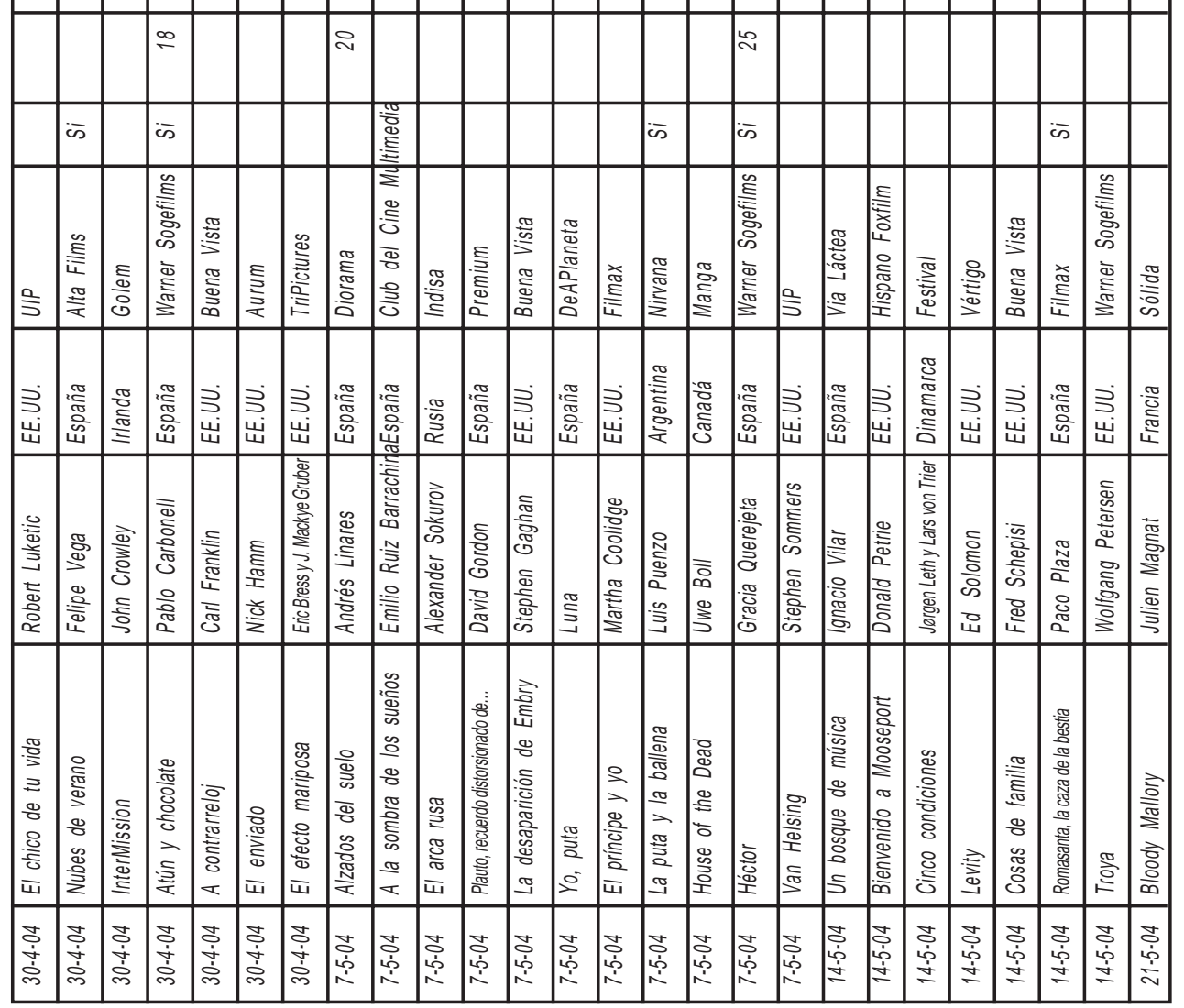




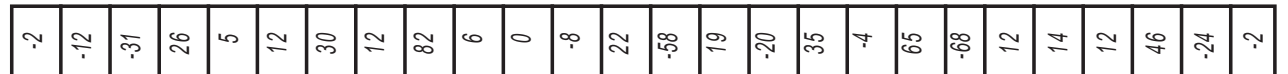
$\infty$ 乎

이 하

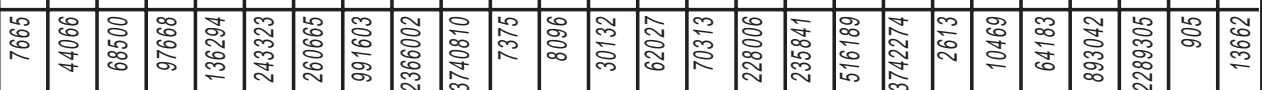

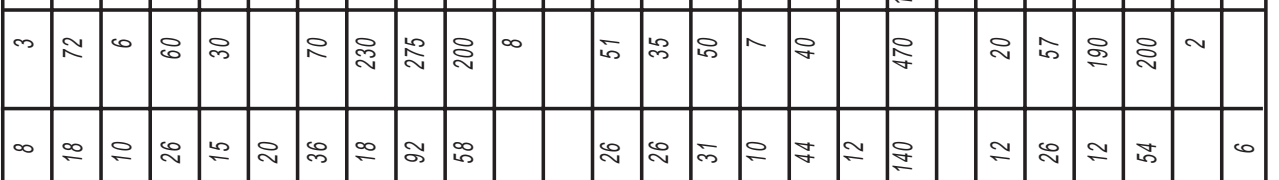

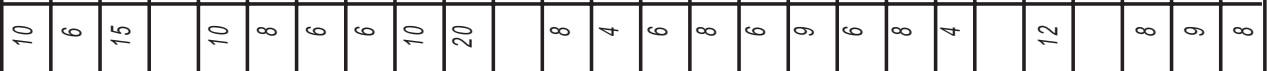
$\stackrel{\sim}{\sim}$

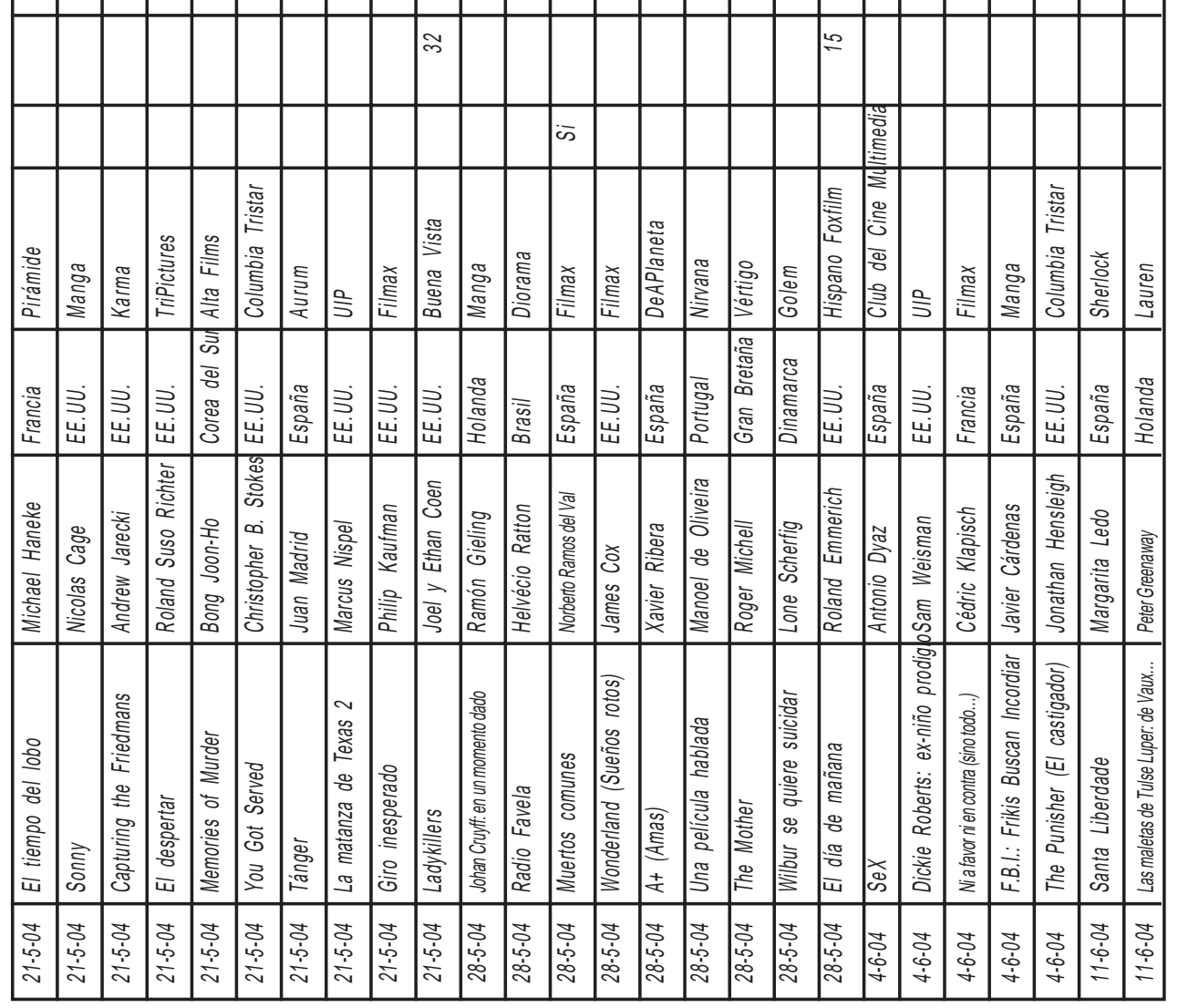




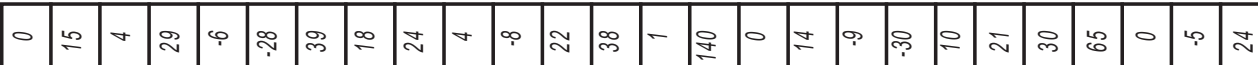

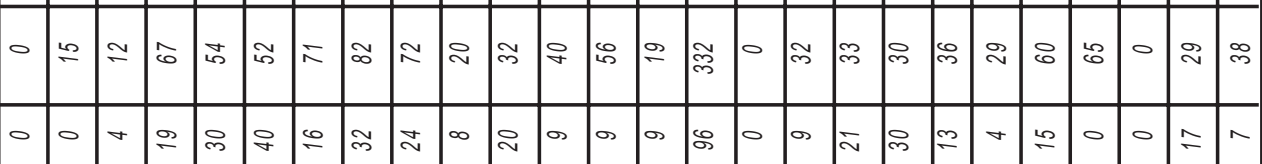

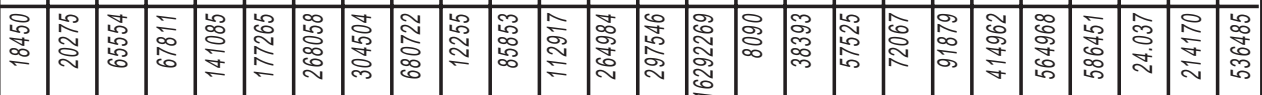

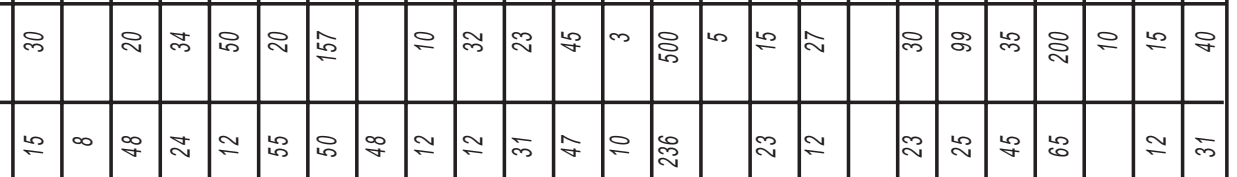

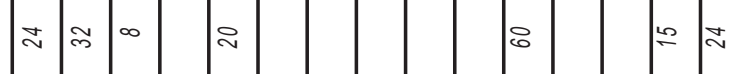

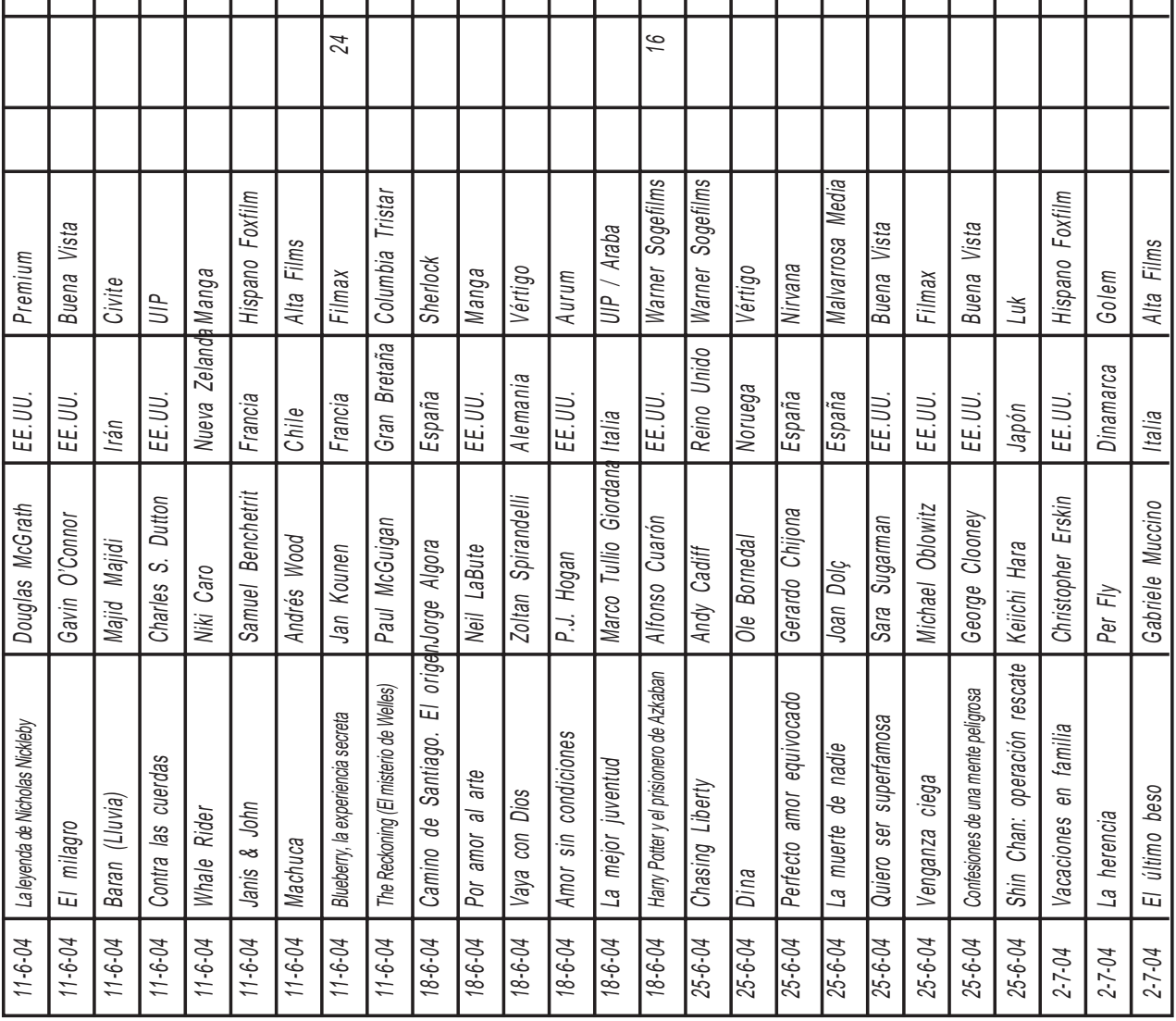




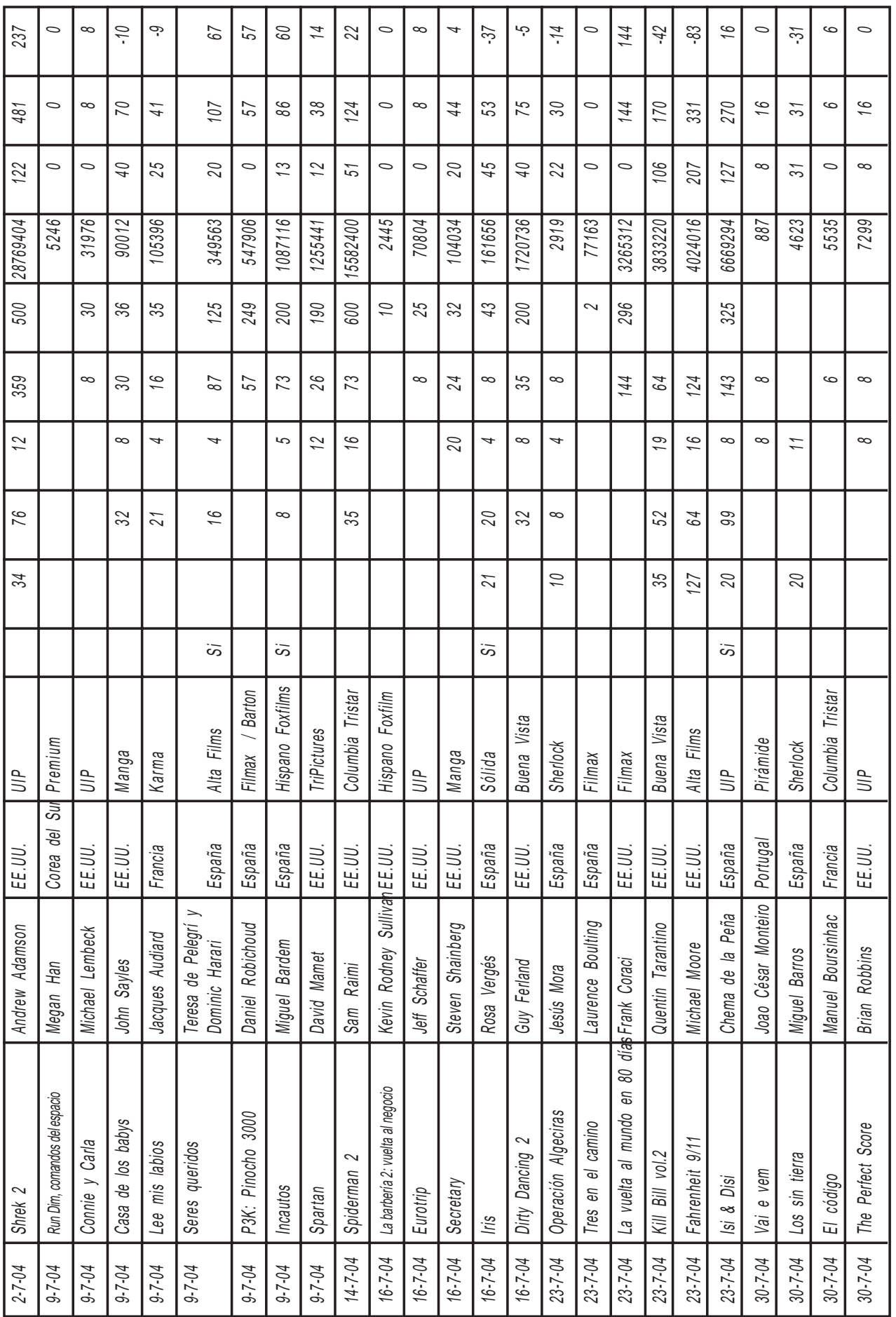




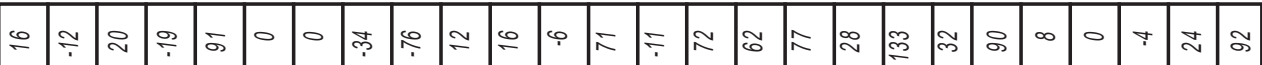
$\infty$ 이

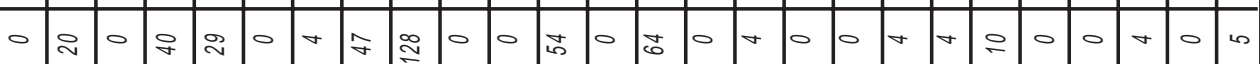

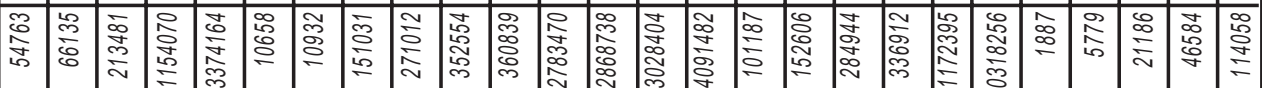

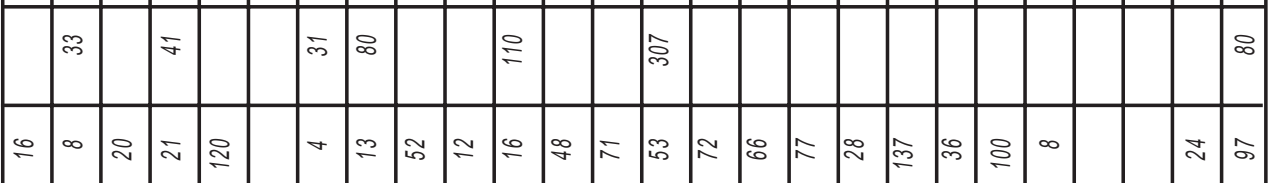

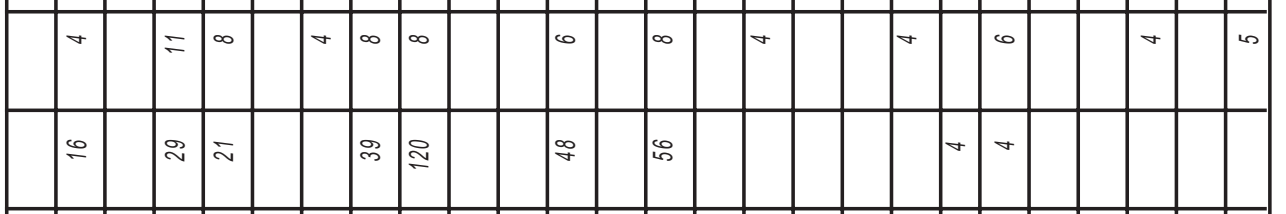

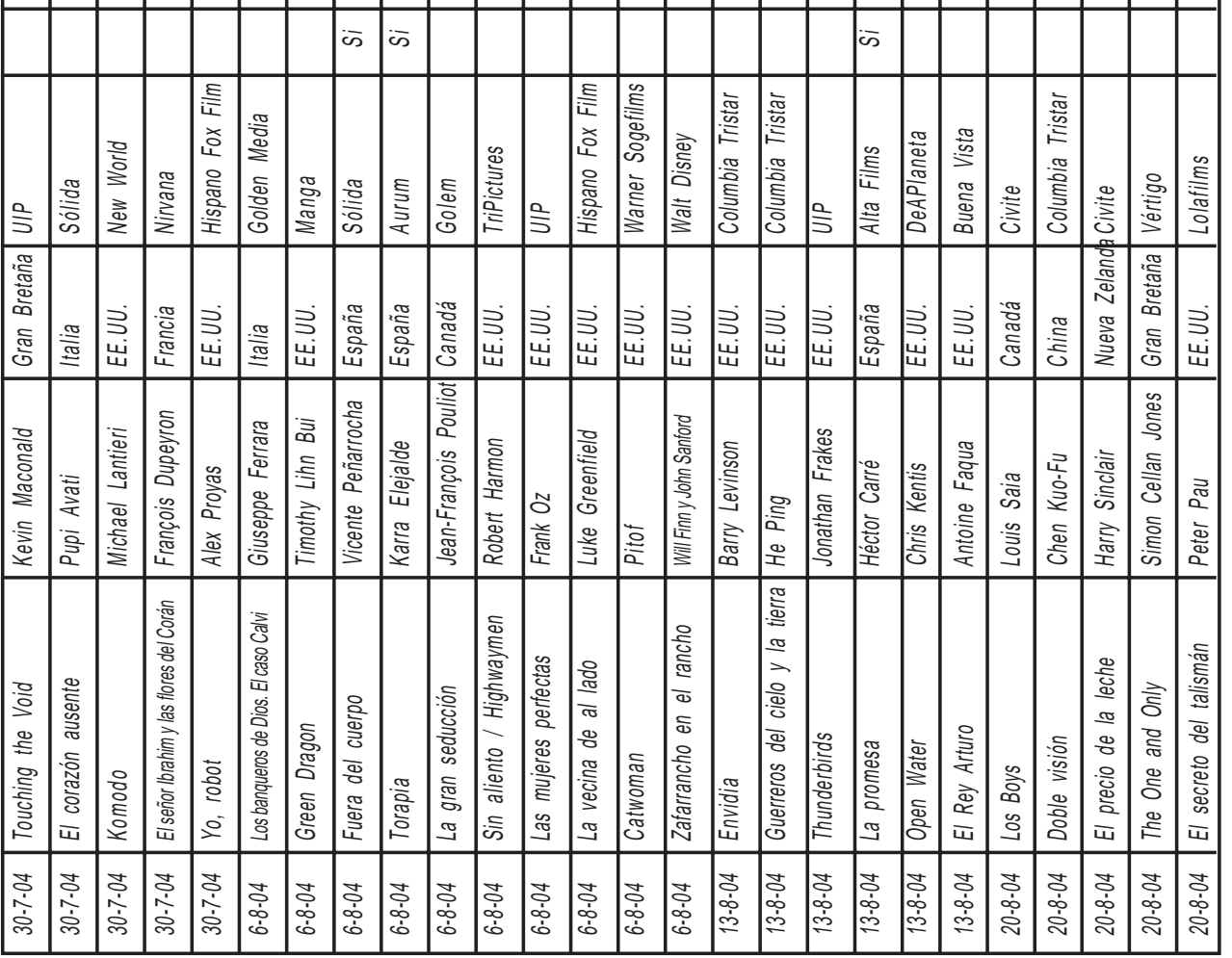




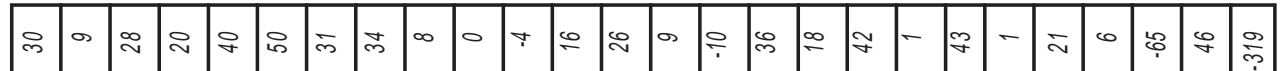
启 0 -

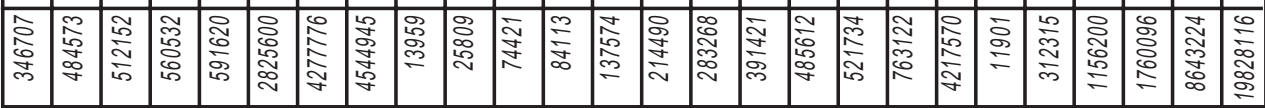

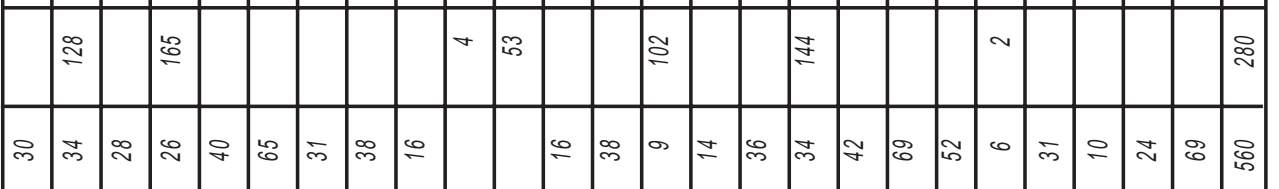

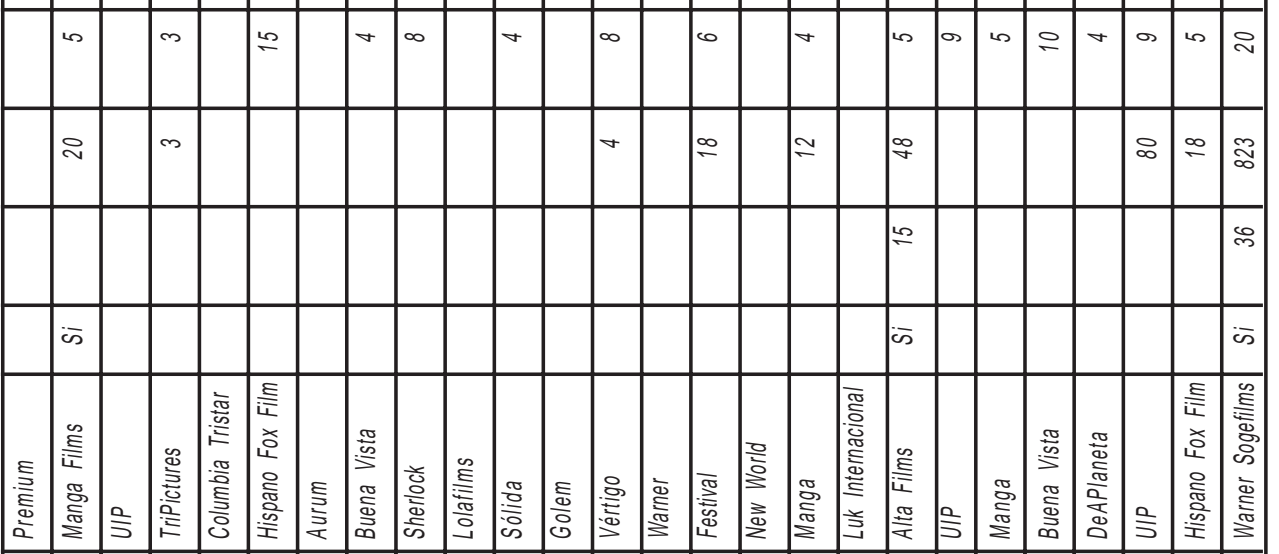

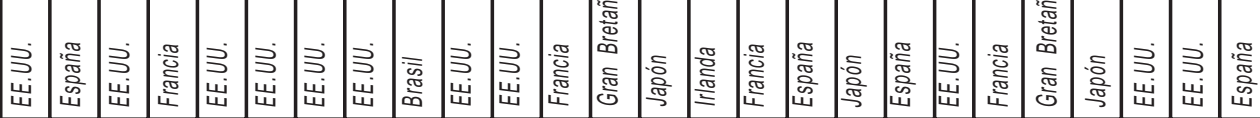

\begin{tabular}{|c|c|c|c|c|c|c|c|c|c|c|c|c|c|c|c|c|c|c|c|c|c|c|c|c|}
\hline$\$$ & 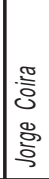 & 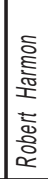 & 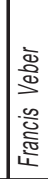 & 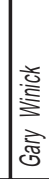 & 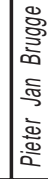 & 13 & 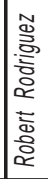 & 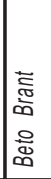 & 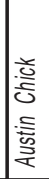 & 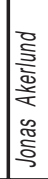 & 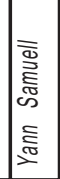 & 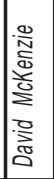 & 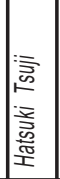 & & 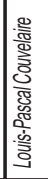 & 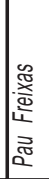 & 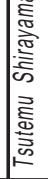 & 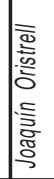 & 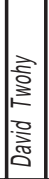 & 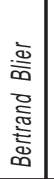 & 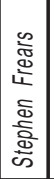 & 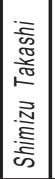 & 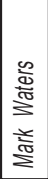 & 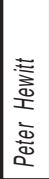 \\
\hline & 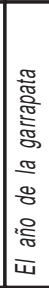 & 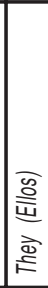 & 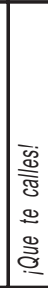 & 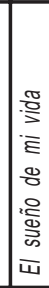 & 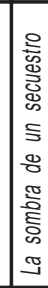 & $\begin{array}{l} \pm \\
0 \\
0 \\
0\end{array}$ & 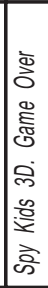 & 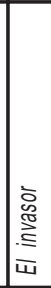 & 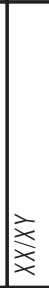 & 咅 & 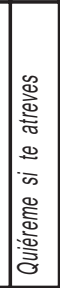 & 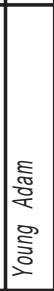 & 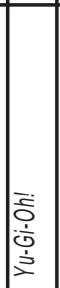 & 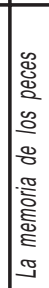 & 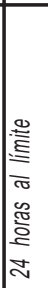 & 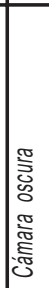 & 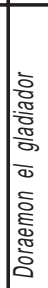 & 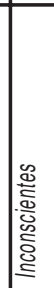 & 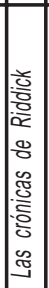 & 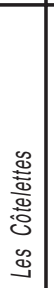 & 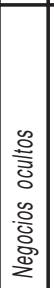 & 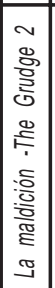 & 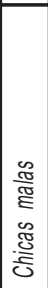 & 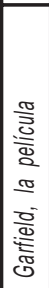 \\
\hline & 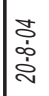 & 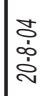 & 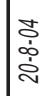 & 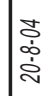 & فे & & চे & 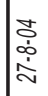 & 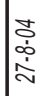 & 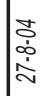 & 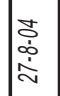 & 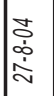 & 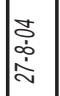 & 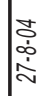 & 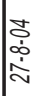 & & & & & $\begin{array}{l}\vec{c} \\
\text { के } \\
\text { 'े }\end{array}$ & 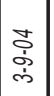 & \begin{tabular}{|c|} 
\\
0 \\
$\dot{\alpha}$ \\
के
\end{tabular} & & \begin{tabular}{|l} 
\\
0 \\
d \\
cे
\end{tabular} \\
\hline
\end{tabular}




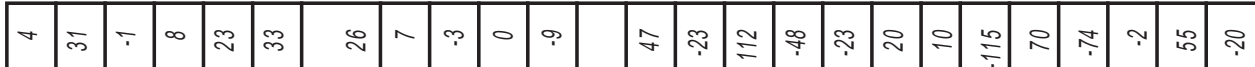
$\approx$ का

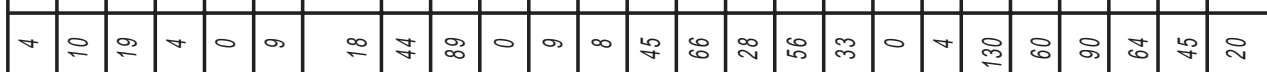

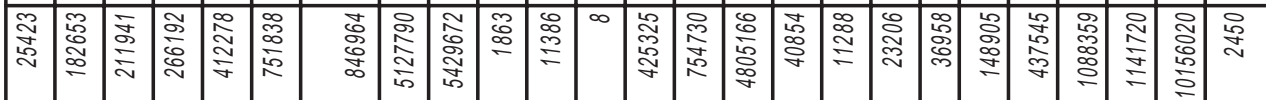

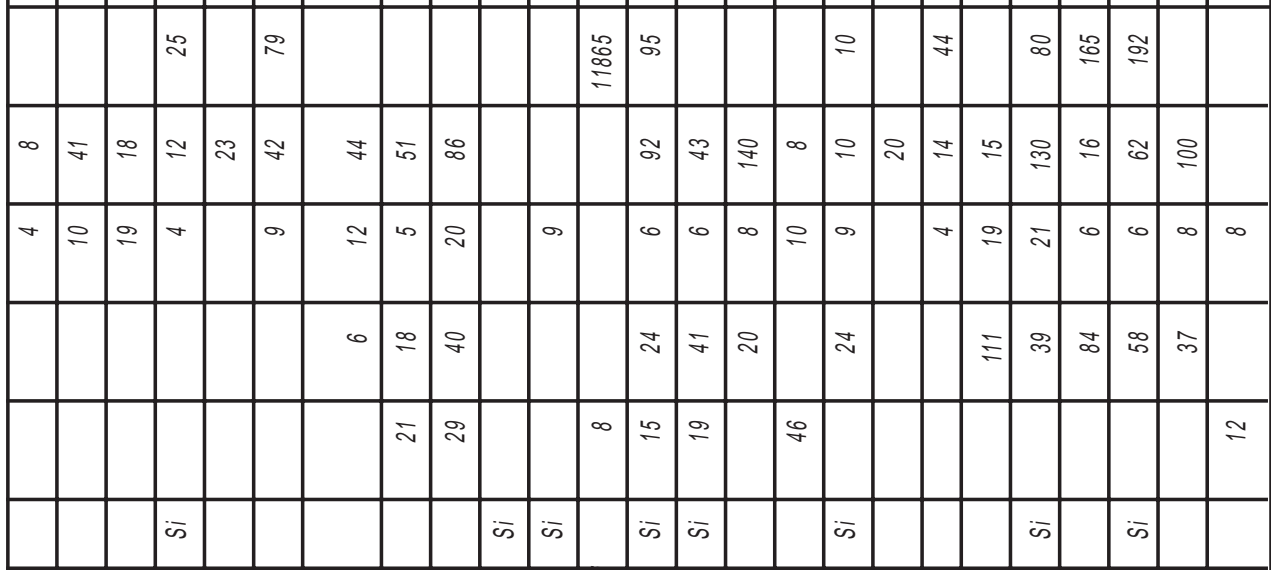

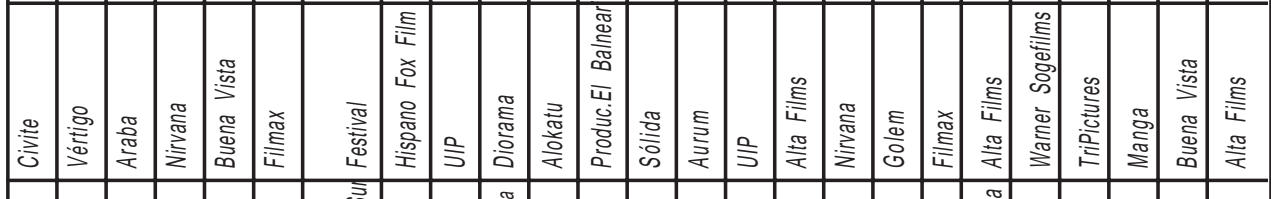

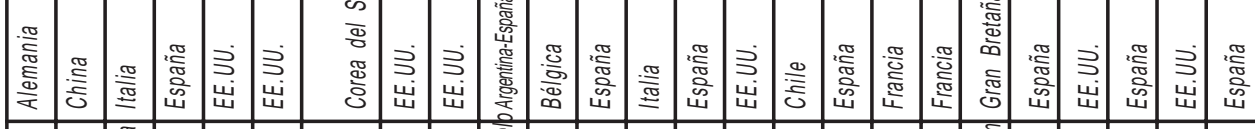

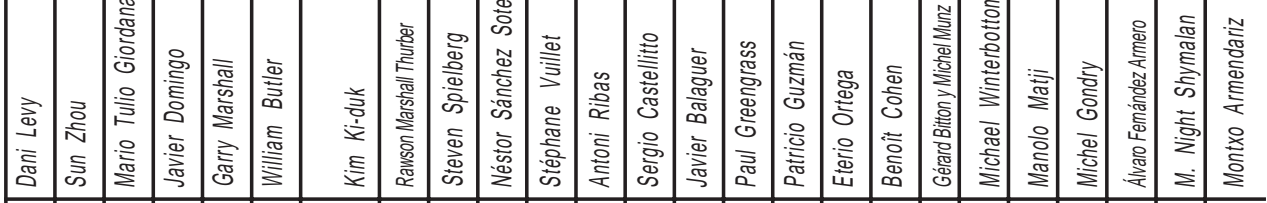

\begin{tabular}{|c|c|c|c|c|c|c|c|c|c|c|c|c|c|c|c|c|c|c|c|c|c|c|c|}
\hline & 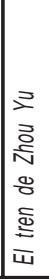 & 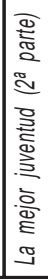 & 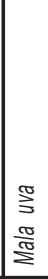 & 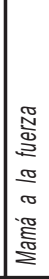 & 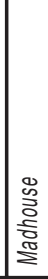 & 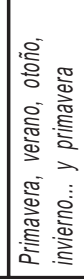 & 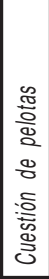 & 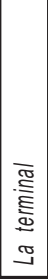 & 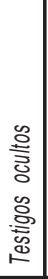 & 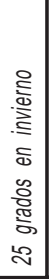 & 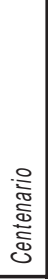 & 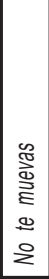 & 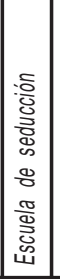 & 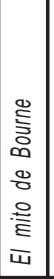 & 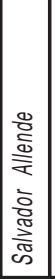 & 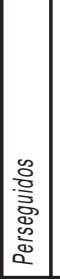 & 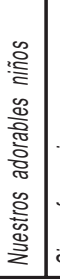 & 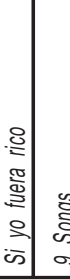 & 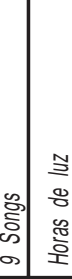 & 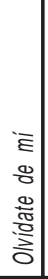 & 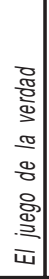 & 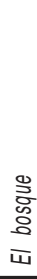 & 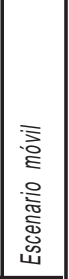 \\
\hline की & $\begin{array}{l}\text { वे } \\
\dot{\alpha} \\
\dot{0}\end{array}$ & $\begin{array}{l}\text { 훙 } \\
\text { के } \\
\text { 엉 }\end{array}$ & $\begin{array}{l}\text { tे } \\
\text { dे } \\
\dot{c}\end{array}$ & $\begin{array}{l}\text { 훙 } \\
\text { के } \\
\text { 응 }\end{array}$ & 章 & 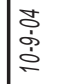 & & \begin{tabular}{l}
\multirow{3}{0}{} \\
d. \\
$\dot{0}$
\end{tabular} & $\begin{array}{l}\text { 홍 } \\
\stackrel{5}{=}\end{array}$ & 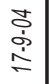 & 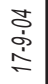 & 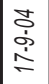 & \begin{tabular}{l}
\multirow{2}{*}{} \\
के \\
$\stackrel{5}{=}$
\end{tabular} & 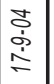 & $\begin{array}{l}\text { के } \\
\text { ஷें } \\
\text { ते }\end{array}$ & \begin{tabular}{|l|} 
\\
d \\
$\dot{d}$ \\
$\dot{d}$
\end{tabular} & 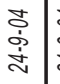 & 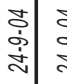 & \begin{tabular}{l|l}
\multicolumn{1}{c}{} & \multicolumn{1}{c}{} \\
\multicolumn{1}{c}{} & \multicolumn{1}{|c}{} \\
$\dot{I}$
\end{tabular} & $\begin{array}{l}+ \\
\text { + } \\
\dot{+}\end{array}$ & $\begin{array}{l}\text { tे } \\
\text { के } \\
\text { d }\end{array}$ & $\begin{array}{l}\text { वे } \\
\text { के } \\
\text { İ }\end{array}$ & \\
\hline
\end{tabular}




\begin{tabular}{|c|c|c|c|c|c|c|c|c|c|c|c|c|c|c|c|c|c|c|c|c|c|c|c|}
\hline$\simeq$ & $\stackrel{\infty}{\dddot{0}}$ & $\stackrel{\infty}{\infty}$ & 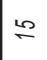 & 8 & $\hat{\sim}$ & $\ddot{m}$ & $\stackrel{\infty}{1}$ & $\stackrel{\sim}{\sim}$ & $\approx$ & శ్ & 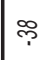 & $\stackrel{2}{2}$ & $\infty$ & $\stackrel{20}{2}$ & $\bar{\sigma}$ & O & $\stackrel{\sim}{\sim}$ & 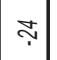 & ঙ্ণ & 0 & क़े & 우 & $\stackrel{\infty}{\infty}$ \\
\hline$\underset{\sim}{ }$ & ¿ర & 号 & க & $\stackrel{\mathbb{2}}{\simeq}$ & శ্ల & is & 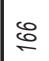 & m & in & $\infty$ & $\infty$ & $\stackrel{8}{9}$ & $\underset{\sim}{\Delta}$ & $\stackrel{\text { L }}{\text { N }}$ & $\approx$ & 定 & $\approx 0$ & 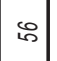 & $\overline{0}$ & 0 & $\stackrel{\infty}{\sim}$ & 으 & $\stackrel{\infty}{\infty}$ \\
\hline$\infty$ & 웅 & ৪ & $\infty$ & $\approx$ & $\stackrel{\infty}{1}$ & 10 & $\cong$ & in & 0 & 它 & $\widetilde{\sigma}$ & 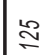 & $\infty$ & 5 & $\infty$ & $\approx$ & 앙 & P & $\approx$ & 0 & mi & 이 & 0 \\
\hline E & 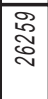 & 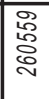 & 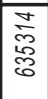 & 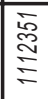 & 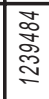 & 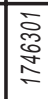 & 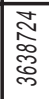 & \begin{tabular}{l} 
芯 \\
\multirow{\sigma}{\sigma}{}
\end{tabular} & $\begin{array}{l}\stackrel{8}{2} \\
\infty \\
=\end{array}$ & 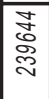 & $\underset{\infty}{\stackrel{m}{m}}$ & 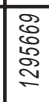 & $\begin{array}{l}\mathbf{E} \\
\infty \\
\infty \\
\infty \\
0\end{array}$ & 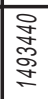 & 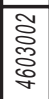 & 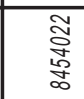 & $\begin{array}{l}\overline{0} \\
\frac{0}{2} \\
\text { m }\end{array}$ & 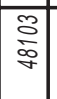 & 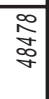 & 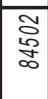 & 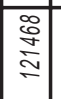 & 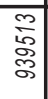 & $\begin{array}{l}\infty \\
\substack{\infty \\
\frac{n}{\infty} \\
\sim}\end{array}$ \\
\hline & & $\approx$ & & & & & & & & $\approx$ & @o & & & & & & & & $\stackrel{\circ}{\sim}$ & & & & \\
\hline$\stackrel{\infty}{\stackrel{0}{2}}$ & $\simeq$ & 응 & $\approx$ & $\hat{\infty}$ & $\frac{n 0}{m}$ & $\approx$ & \& & $\bar{m}$ & $\approx$ & $\approx$ & $\underset{\sim}{Z}$ & న & $\stackrel{\circ}{\circ}$ & $\stackrel{ }{=}$ & ( & నิ & $\simeq$ & 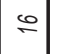 & \pm & & $\stackrel{\infty}{\sigma}$ & & $\stackrel{\infty}{\infty}$ \\
\hline$\infty$ & $\infty$ & $\simeq$ & $\infty$ & $\infty$ & : & os & $\underset{\square}{ }$ & in & & $\simeq$ & $\infty$ & ما & $\infty$ & $\infty$ & $\infty$ & $\stackrel{20}{n}$ & $\infty$ & $\infty$ & \pm & & 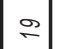 & 으 & \\
\hline & ల్ల & & & $\underset{\sim}{\beth}$ & $\widetilde{\text { ) }}$ & & $\infty$ & & & $\infty$ & 媇 & $\underset{ }{\simeq}$ & & ఇా & & & $\approx$ & $\underset{\sim}{ \pm}$ & m & & ิ & & \\
\hline & & $\stackrel{\infty}{\sim}$ & & & $\stackrel{\sim}{\sim}$ & & 앙 & & & $\underset{\sim}{\sim}$ & & & & in & & $\simeq$ & & 으 & & & & & \\
\hline & & के & & க் & $\overline{\substack{s \\
\tilde{\sigma}}}$ & & & & & & & के & & & & & & & & & & & \\
\hline$\stackrel{\circ}{5}$ & 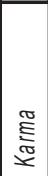 & 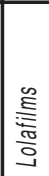 & 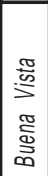 & 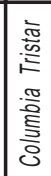 & 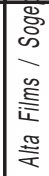 & 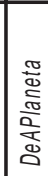 & 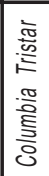 & 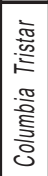 & 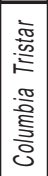 & 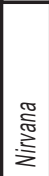 & 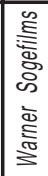 & $\frac{\mathrm{D}}{\overline{3}}$ & 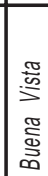 & 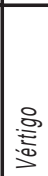 & 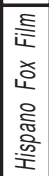 & $\stackrel{\circ}{5}$ & 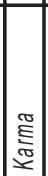 & 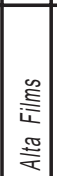 & 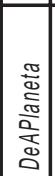 & 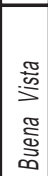 & 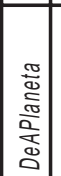 & 혼 & 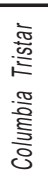 \\
\hline 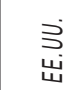 & 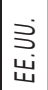 & 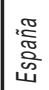 & 岃 & 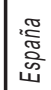 & 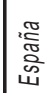 & 蛋 & $\underset{\text { 出 }}{\lessgtr}$ & $\underset{\mathrm{u}}{\mathrm{u}}$ & 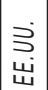 & 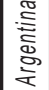 & $\underset{\text { 岃 }}{\text { 㟧 }}$ & 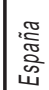 & 出 & $\underset{\text { 出 }}{3}$ & $\underset{\text { 出 }}{3}$ & 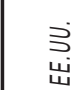 & $\mid$\begin{tabular}{r|}
$-\frac{\pi}{0}$ \\
$\frac{0}{5}$ \\
$\frac{\pi}{4}$
\end{tabular} & $\mid \begin{array}{c}\frac{\pi}{0} \\
\frac{\pi}{\pi} \\
\frac{\pi}{4}\end{array}$ & 壱 & \begin{tabular}{|c} 
㠀 \\
|
\end{tabular} & $\mid \begin{array}{c}3 \\
\text { 出 }\end{array}$ & 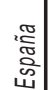 & $\underset{\text { 出 }}{\stackrel{3}{\text { S }}}$ \\
\hline 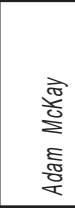 & 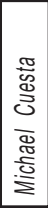 & 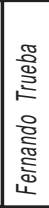 & 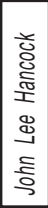 & 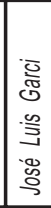 & 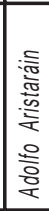 & 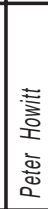 & 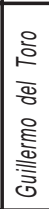 & 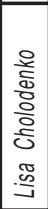 & 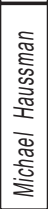 & 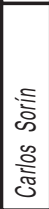 & 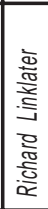 & 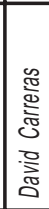 & 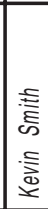 & 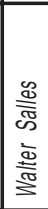 & 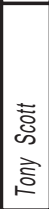 & 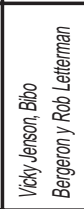 & 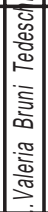 & 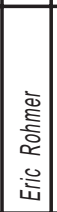 & 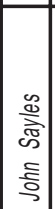 & 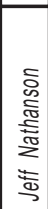 & 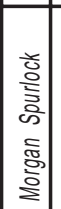 & 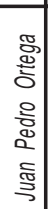 & 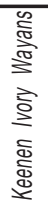 \\
\hline 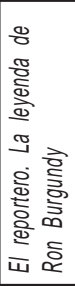 & 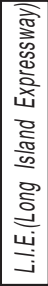 & 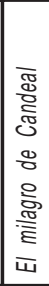 & 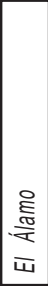 & 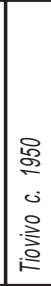 & $\mid \begin{array}{l}\widetilde{\sigma} \\
\tilde{\Sigma} \\
\propto\end{array}$ & 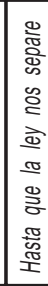 & $\frac{\overline{0}}{\frac{0}{\mathrm{a}}}$ & 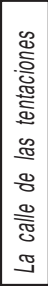 & 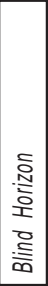 & 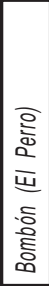 & 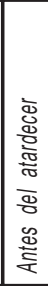 & 訔 & 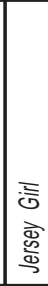 & 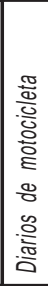 & 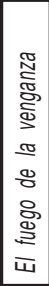 & 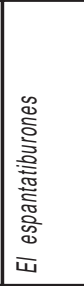 & 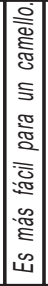 & 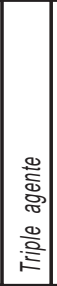 & $\begin{array}{l}\overrightarrow{0} \\
\stackrel{\vec{D}}{\text { के }}\end{array}$ & 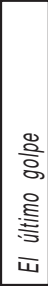 & 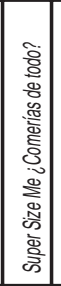 & $\begin{array}{c} \\
: \frac{0}{3} \\
\end{array}$ & 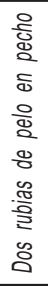 \\
\hline 总 & 常 & 훌 & 蒙 & 훙 & 咅 & 竞 & 훌 & $\underset{\infty}{\stackrel{+}{c}}$ & $\underset{\infty}{\stackrel{d}{c}}$ & $\frac{+}{\dot{0}}$ & 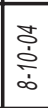 & 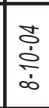 & 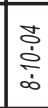 & $\frac{+}{\dot{0}}$ & $\frac{1}{0}$ & 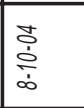 & 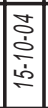 & 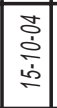 & $\begin{array}{l}\text { 후 } \\
\text { 울 } \\
\text { in }\end{array}$ & \begin{tabular}{|l|}
+ \\
$\dot{0}$ \\
$\dot{1}$ \\
$\dot{1}$
\end{tabular} & \begin{tabular}{|c|} 
\\
$\dot{0}$ \\
$\dot{c}$ \\
$\dot{2}$ \\
\end{tabular} & 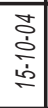 & 定 \\
\hline
\end{tabular}




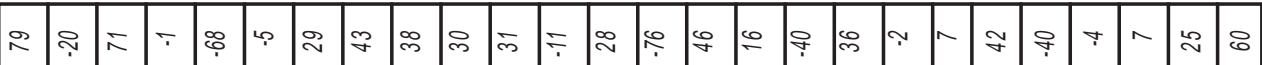

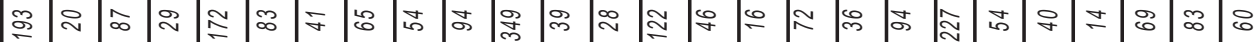

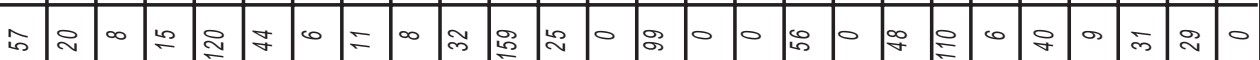

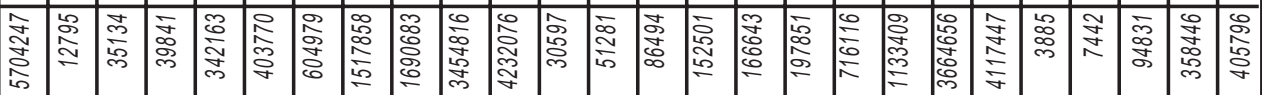

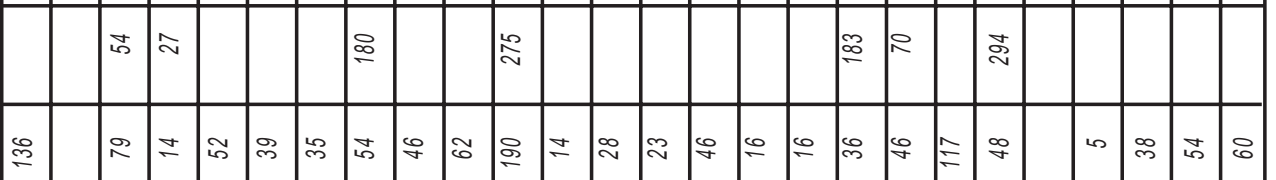

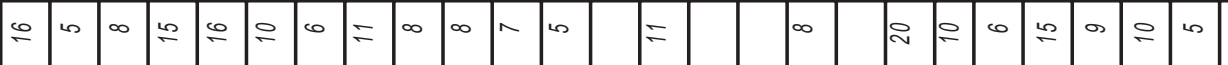

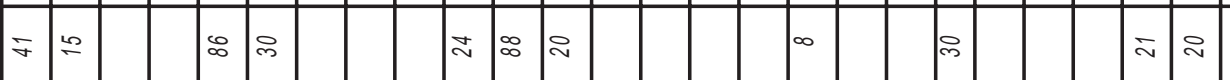

\begin{tabular}{|c|c|c|c|c|c|c|c|c|c|c|c|c|c|c|c|c|c|c|c|c|c|c|c|c|c|}
\hline & & & & $\infty$ & $\nabla$ & & & & & is & & & $\infty$ & & & lo & & $\approx$ & $R$ & & $\stackrel{2}{\sim}$ & & & $\forall$ & \\
\hline & & & & & & & & & & க் & कি & & & ís & & & & & & & क & & & & \\
\hline$\frac{a}{5}$ & 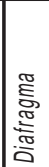 & $\frac{a}{3}$ & 敢 & \begin{tabular}{|l|} 
\\
$\frac{0}{0}$ \\
0
\end{tabular} & 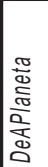 & 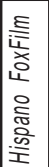 & 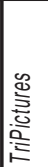 & 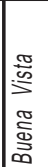 & 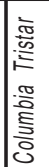 & 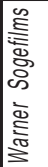 & 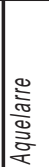 & 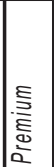 & 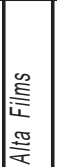 & 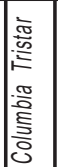 & 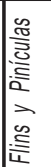 & $\begin{array}{l}\mathbb{\pi} \\
\substack{\pi \\
\frac{\pi}{x}}\end{array}$ & 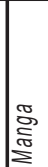 & 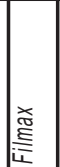 & 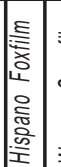 & 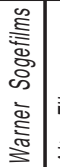 & 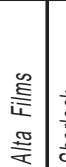 & $\begin{array}{l}\text { 흘 } \\
\text { के } \\
\text { के }\end{array}$ & $\frac{a}{5}$ & s. & 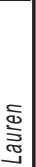 \\
\hline 岕 & 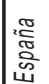 & 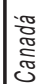 & 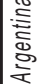 & 悹 & 岕 & 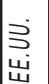 & 恿 & 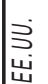 & 穴 & 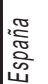 & $\frac{\pi}{\frac{\pi}{\pi}}$ & 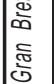 & 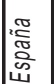 & 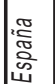 & 空 & 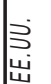 & 令 & 念 & 空 & $\underset{\text { 出 }}{\stackrel{3}{ }}$ & 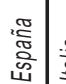 & 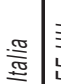 & 空 & $\frac{\pi}{\frac{\pi}{2}}$ & 恿 \\
\hline 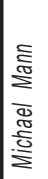 & 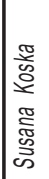 & 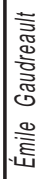 & 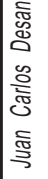 & 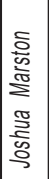 & 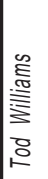 & 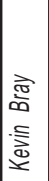 & 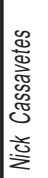 & 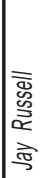 & 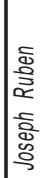 & 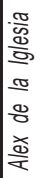 & 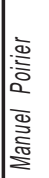 & 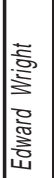 & 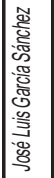 & 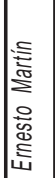 & 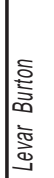 & 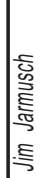 & 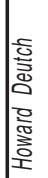 & 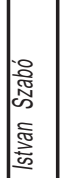 & 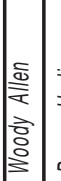 & 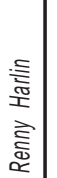 & 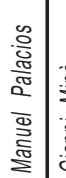 & 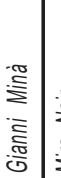 & 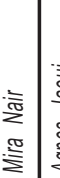 & 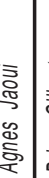 & 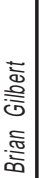 \\
\hline 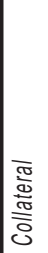 & 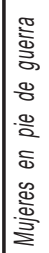 & 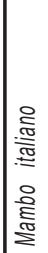 & 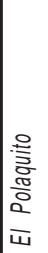 & 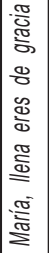 & 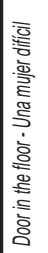 & 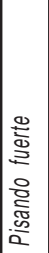 & 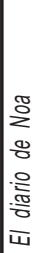 & 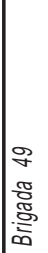 & 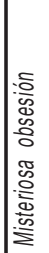 & 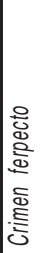 & 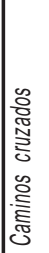 & 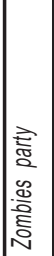 & 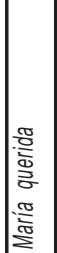 & 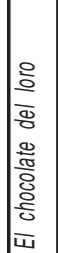 & 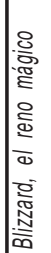 & 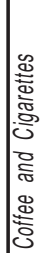 & 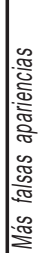 & 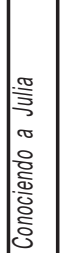 & 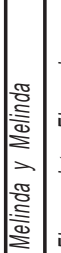 & 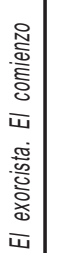 & 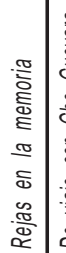 & 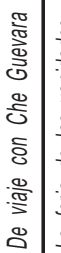 & 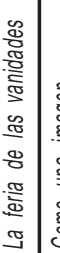 & 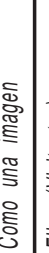 & 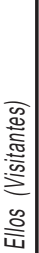 \\
\hline 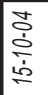 & $\begin{array}{l}\frac{0}{\dot{0}} \\
\dot{0} \\
\dot{\tilde{\Delta}}\end{array}$ & $\begin{array}{l}\dot{0} \\
\dot{0} \\
\text { ते }\end{array}$ & $\begin{array}{l}\dot{0} \\
\dot{\dot{\delta}} \\
\text { ते }\end{array}$ & 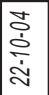 & 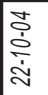 & $\begin{array}{l}\frac{1}{\dot{c}} \\
\dot{0} \\
\dot{\tilde{\Delta}}\end{array}$ & 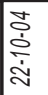 & $\begin{array}{l}\dot{0} \\
\dot{0} \\
\dot{\tilde{\Delta}} \\
\dot{\sim}\end{array}$ & 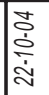 & 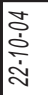 & 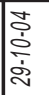 & 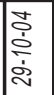 & 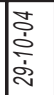 & 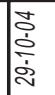 & 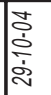 & 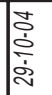 & 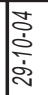 & 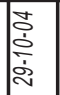 & 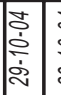 & $\begin{array}{l}\text { पे } \\
\dot{c} \\
\dot{\mathbf{N}}\end{array}$ & 它 & 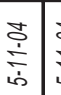 & 孛 & $\frac{⿱ 亠 䒑}{i}$ & $\frac{+}{\frac{1}{\bar{\dagger}}}$ \\
\hline
\end{tabular}




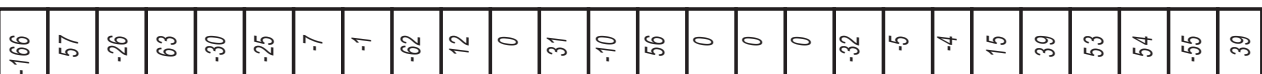

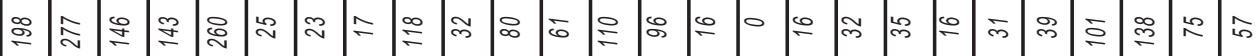

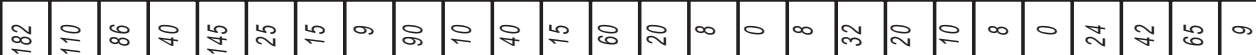

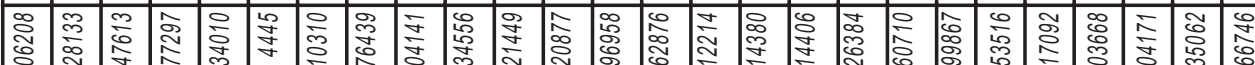

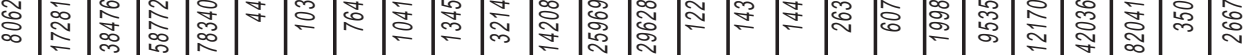

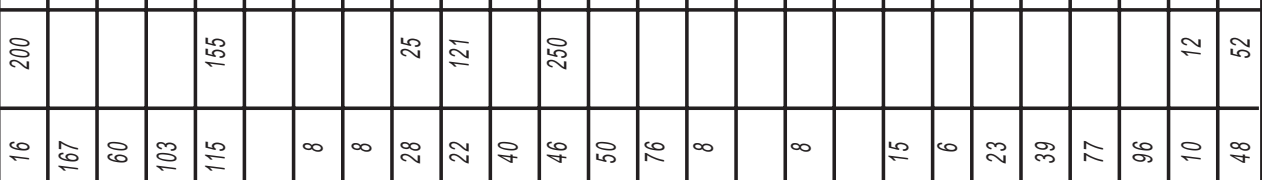

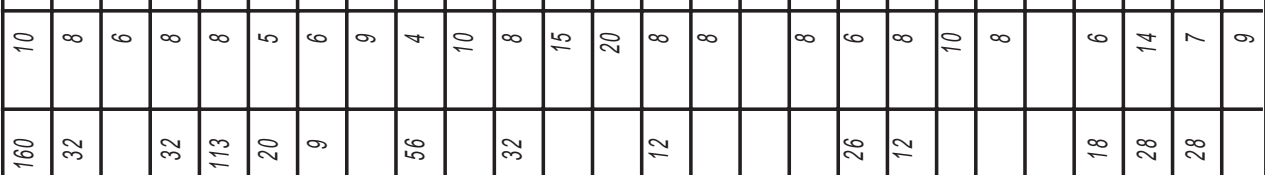

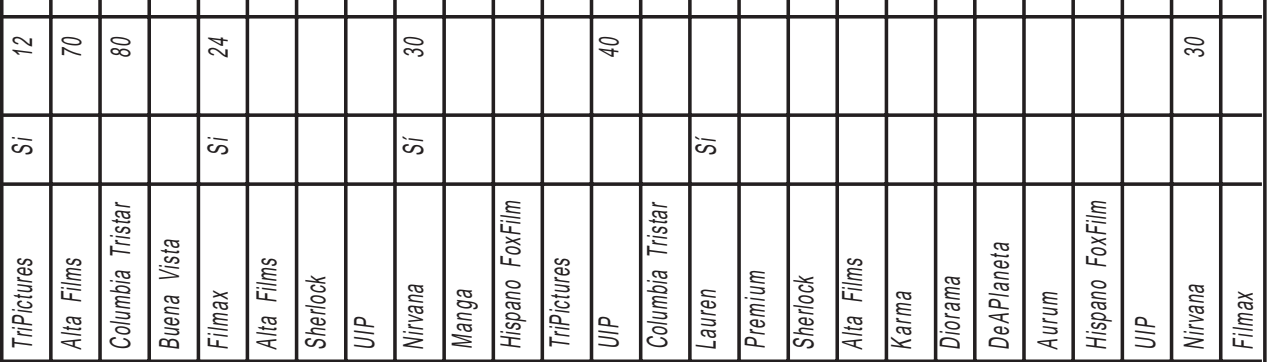

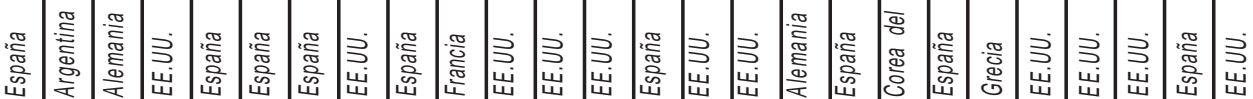

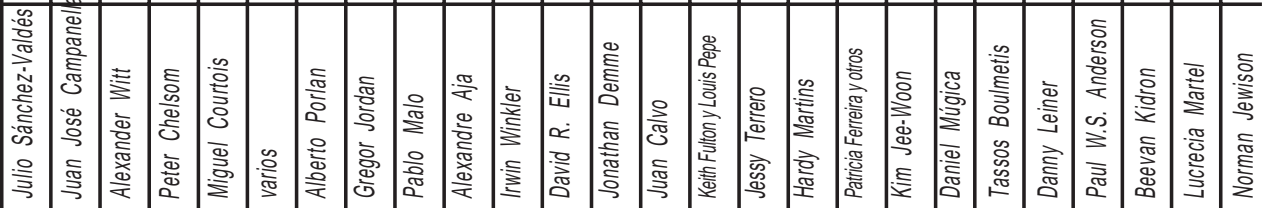

\begin{tabular}{|c|c|c|c|c|c|c|c|c|c|c|c|c|c|c|c|c|c|c|c|c|c|c|c|c|c|}
\hline$\underset{x}{x}$ & 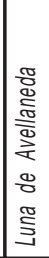 & 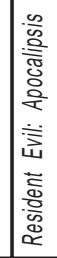 & 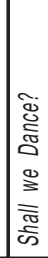 & \begin{tabular}{|l|} 
\\
\\
\\
\end{tabular} & $\begin{array}{l}\text { 辛 } \\
\text { E } \\
\text { 离 }\end{array}$ & 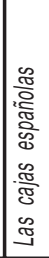 & 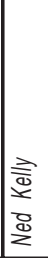 & 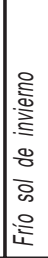 & 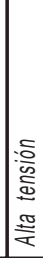 & $\begin{array}{l}\text { बे } \\
\text { जे } \\
\text { वे }\end{array}$ & 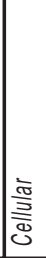 & 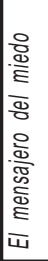 & $\begin{array}{l}\bar{w} \\
\bar{y} \\
\bar{y} \\
\bar{a}\end{array}$ & 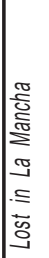 & 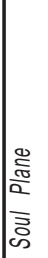 & 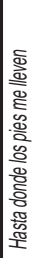 & 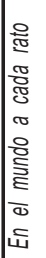 & 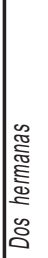 & 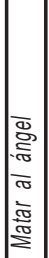 & 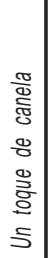 & 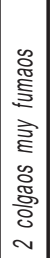 & 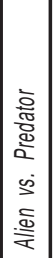 & 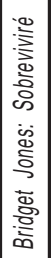 & 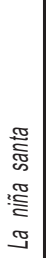 & \\
\hline 章 & $\frac{+}{\frac{1}{6}}$ & $\frac{+}{\stackrel{+}{-}}$ & $\frac{\frac{1}{9}}{\dot{0}}$ & $\frac{\text { 家 }}{\frac{1}{4}}$ & 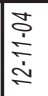 & 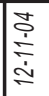 & 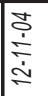 & 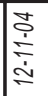 & 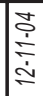 & $\frac{1}{10}$ & 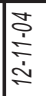 & 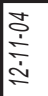 & 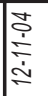 & 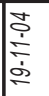 & 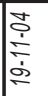 & & & 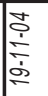 & 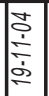 & 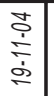 & 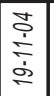 & 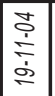 & 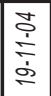 & 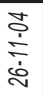 & \\
\hline
\end{tabular}




\begin{tabular}{|c|c|c|c|c|c|c|c|c|c|c|c|c|c|c|c|c|c|c|c|c|c|c|c|}
\hline 苫 & $?$ & $\sim$ & in & 0 & 导 & $\nabla$ & $\stackrel{\infty}{\sim}$ & $\approx$ & 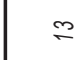 & $\infty$ & is & $1 \%$ & $\approx$ & & ימ & $\stackrel{m}{\div}$ & 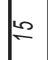 & $\approx$ & $\underset{\sim}{\mathbb{Z}}$ & $\simeq$ & $\hat{?}$ & $\underset{T}{\sim}$ & 0 \\
\hline 总 & $\approx$ & 文 & co & 0 & స్లి & $\therefore$ & q & হ & ? & $\approx$ & జ & 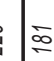 & $\stackrel{2}{2} \div$ & & 5 & $\mathscr{q}$ & 28 & $\approx$ & 守 & in & in & $\mathbb{\sim}$ & ন \\
\hline హ) & $E$ & ఝొ & مמ & 0 & \& & $\infty$ & 0 & $\stackrel{\circ}{\circ}$ & $\stackrel{2}{*}$ & $\approx$ & $\Re$ & 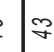 & 10 & & $\stackrel{\infty}{\sim}$ & $\stackrel{\infty}{\sim}$ & F & $\stackrel{2}{\sim}$ & 吉 & I & 15 & $\underset{\sim}{\Delta}$ & 으 \\
\hline 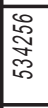 & 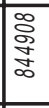 & $\begin{array}{l}\text { 志 } \\
\frac{1}{\sigma} \\
\frac{1}{5}\end{array}$ & 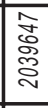 & \begin{tabular}{|l} 
孚 \\
号 \\
․
\end{tabular} & $\begin{array}{l}\bar{E} \\
0 \\
0 \\
0 \\
0 \\
\end{array}$ & 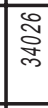 & $\begin{array}{l}\infty \\
\infty \\
\infty \\
\infty\end{array}$ & 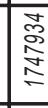 & 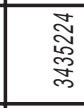 & $\begin{array}{l}\infty \\
\frac{m}{\sigma} \\
\infty \\
\infty \\
\infty\end{array}$ & 亲 & 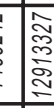 & 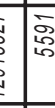 & & 2 & \begin{tabular}{l} 
o \\
$\ll$ \\
\hdashline 0 \\
\hdashline
\end{tabular} & 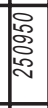 & 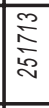 & 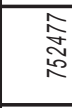 & 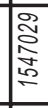 & 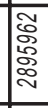 & 竞 & $\mid \begin{array}{l}\mathbb{a} \\
\infty \\
\infty\end{array}$ \\
\hline & & & & & & & & ڤ్ & \& & ফ্ল্লে & & & & & & & & & ని & & & & \\
\hline P & $\bar{\gamma}$ & 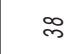 & ช్ర & & 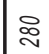 & $\cong$ & ా & $\infty$ & is & 음 & $\approx$ & $\stackrel{\infty}{m}$ & $\approx$ & & $\tilde{D}$ & 20 & in & $\neq$ & $\approx$ & లి & i & & 으 \\
\hline ح & $\infty$ & 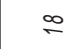 & osi & & ㄱ & $\infty$ & $\infty$ & $\stackrel{\circ}{\circ}$ & $\infty$ & $\stackrel{\circ}{\circ}$ & $\infty$ & $1=$ & & & 6 & $\infty$ & $\infty$ & $\infty$ & $\bar{\sim}$ & $\nabla$ & os & os & 응 \\
\hline F & $\bar{\sigma}$ & $\infty$ & & & ㄱ & & & & $\stackrel{9}{\longrightarrow}$ & & $\bar{z}$ & $1 \approx$ & & & & ন & $\approx$ & O & $\cong$ & 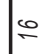 & $\approx$ & 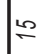 & \\
\hline 苂 & $\approx$ & & & & & & & & ని & 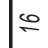 & $\not{\sim}$ & & & & $\cong$ & & & & $\infty$ & & os & & \\
\hline & & is & & & & & & & के & & & & & & & & & & & & & & \\
\hline 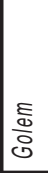 & 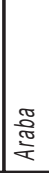 & 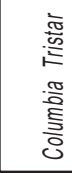 & 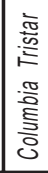 & 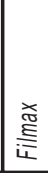 & 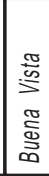 & $\frac{\mathrm{a}}{3}$ & 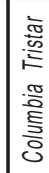 & 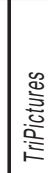 & 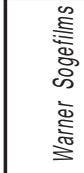 & 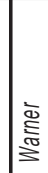 & 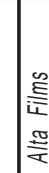 & 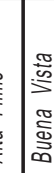 & 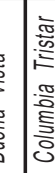 & s. & 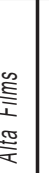 & 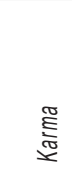 & 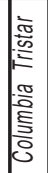 & 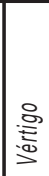 & 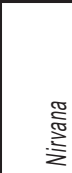 & $\frac{2}{5}$ & 旁 & 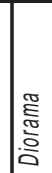 & 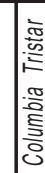 \\
\hline 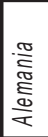 & 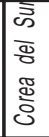 & 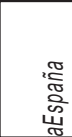 & 炎 & 灾 & 㤀 & 蛋 & 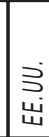 & $\begin{array}{l}\frac{\pi}{0} \\
\frac{\mathbb{\pi}}{4} \\
\frac{\pi}{L}\end{array}$ & 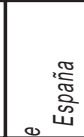 & 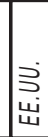 & 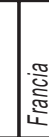 & 出 & نُ & 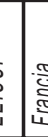 & 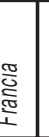 & 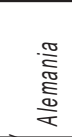 & 息 & 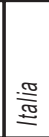 & 호옳 & 芯 & $\underset{\text { 岕 }}{\text { 岃 }}$ & 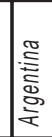 & $\mid \begin{array}{l}\mathbb{\pi} \\
\mathbb{\widetilde { J }} \\
\mathbb{J} \\
\mathbb{J}\end{array}$ \\
\hline 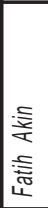 & 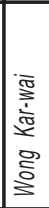 & 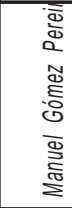 & 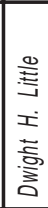 & 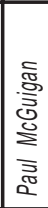 & 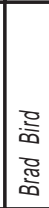 & $\begin{array}{l}\overline{\bar{\Phi}} \\
\text { 产 } \\
\text { के } \\
\text { 产 }\end{array}$ & 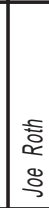 & 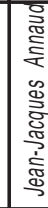 & 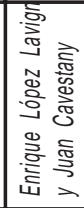 & 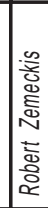 & 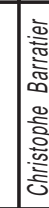 & 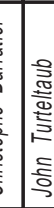 & 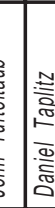 & 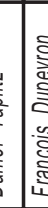 & 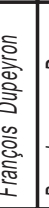 & 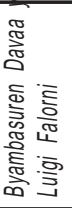 & 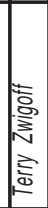 & 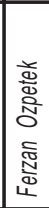 & 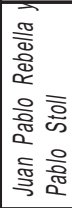 & 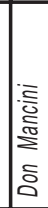 & 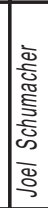 & 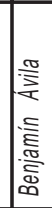 & 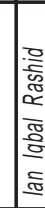 \\
\hline 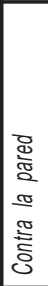 & \begin{tabular}{l}
0 \\
\multirow{2}{*}{}
\end{tabular} & 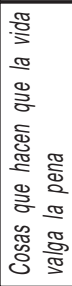 & 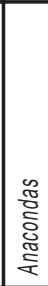 & 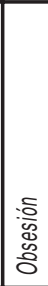 & 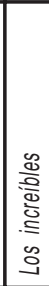 & 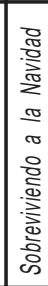 & 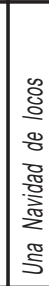 & 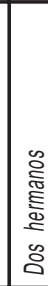 & 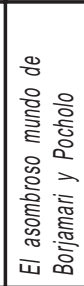 & 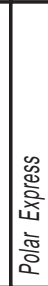 & 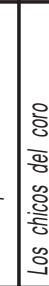 & 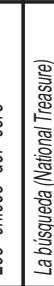 & 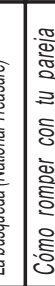 & 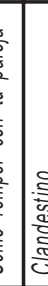 & 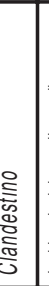 & 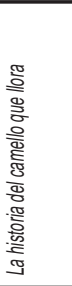 & 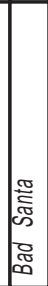 & 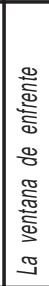 & 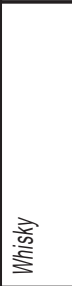 & 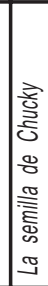 & 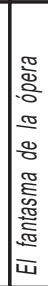 & 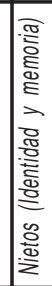 & 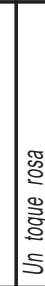 \\
\hline 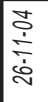 & 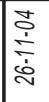 & 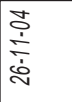 & 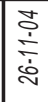 & 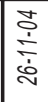 & 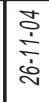 & $\frac{\dot{d}}{\dot{\Delta}}$ & 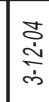 & $\frac{\vec{d}}{\dot{c}}$ & $\underset{\dot{\sim}}{\stackrel{+}{\dot{d}}}$ & $\frac{\dot{d}}{\stackrel{\dot{\alpha}}{\dot{~}}}$ & $\mid \begin{array}{c}\stackrel{\Delta}{\sim} \\
\dot{\sim}\end{array}$ & $\frac{\vec{d}}{\stackrel{d}{\dot{m}}}$ & 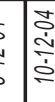 & 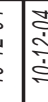 & 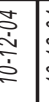 & 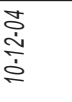 & 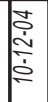 & 竞 & 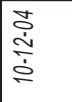 & 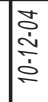 & $\begin{array}{l}\text { 完 } \\
\text { ì } \\
\text { in }\end{array}$ & 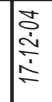 & 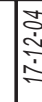 \\
\hline
\end{tabular}




\begin{tabular}{|c|c|c|c|c|c|c|c|c|c|c|c|c|c|c|c|c|c|}
\hline$\stackrel{\infty}{\sim}$ & 용 & $\stackrel{\infty}{=}$ & $\approx$ & 8 & n & $\simeq$ & $\stackrel{n}{?}$ & $\infty$ & $\stackrel{\infty}{\sim}$ & 20 & $\Phi$ & $\approx$ & $\infty$ & $\div$ & is & 으 & $\nabla$ \\
\hline$\stackrel{\infty}{\simeq}$ & $\stackrel{g}{+}$ & $\infty$ & $\approx$ & $\cong$ & $\stackrel{28}{2}$ & a & $\bar{m}$ & $\infty$ & $\infty$ & $\&$ & 놈 & $\infty$ & os & $\infty$ & os & 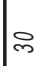 & 8 \\
\hline 0 & 8 & 0 & 0 & $\bar{z}$ & 8 & $\sigma$ & $\widetilde{\sim}$ & లి & 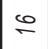 & $\infty$ & $\stackrel{\cong}{\cong}$ & $\infty$ & $\forall$ & $\stackrel{\infty}{\simeq}$ & os & 은 & $\infty$ \\
\hline \begin{tabular}{l}
$\frac{5}{0}$ \\
$\infty$ \\
\hdashline
\end{tabular} & 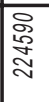 & 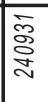 & 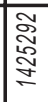 & 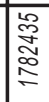 & 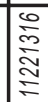 & 点 & 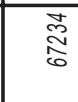 & 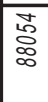 & $\begin{array}{l}\mathscr{8} \\
8 \\
\infty \\
\infty \\
\infty\end{array}$ & 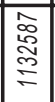 & 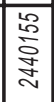 & $\begin{array}{l}\overrightarrow{8} \\
8 \\
\vdots \\
\vdots \\
\sigma\end{array}$ & 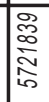 & 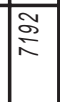 & 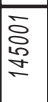 & 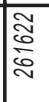 & $\begin{array}{l}\infty \\
\infty \\
\infty \\
\infty \\
\infty \\
\infty\end{array}$ \\
\hline ఎ & & in & & $\stackrel{\simeq}{\simeq}$ & 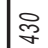 & & $\approx$ & & & & & & & & & & $\stackrel{\infty}{\circ}$ \\
\hline$\stackrel{\infty}{\simeq}$ & ¿ & $\infty$ & $\approx$ & $\infty$ & 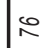 & $\stackrel{\circ}{\circ}$ & $\infty$ & ల) & 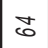 & $\mid \begin{array}{l}\infty \\
\infty\end{array}$ & శ్ & 8 & ळ & & & ฉ & $\approx$ \\
\hline & os & & & $\sigma$ & $\infty$ & $\sigma$ & in & 0 & 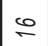 & $\infty$ & ح & $\infty$ & 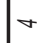 & $\simeq$ & os & $\therefore$ & $\infty$ \\
\hline & 6 & & & $\hat{\text { m }}$ & $\bar{\gamma}$ & & $\stackrel{\infty}{\stackrel{0}{2}}$ & $\stackrel{\sim}{\sim}$ & & & $\stackrel{\infty}{\sim}$ & & & $\infty$ & & & \\
\hline & & & & & ฉ & & & & & & $\leqslant 2$ & & & & & & \\
\hline & & & & के & & & & & & ळ & & & & & & & \\
\hline 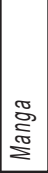 & 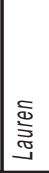 & 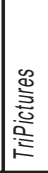 & 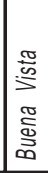 & 离 & 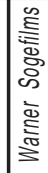 & 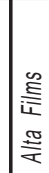 & 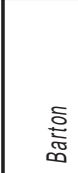 & $\begin{array}{l}\text { 흐 } \\
\frac{0}{\bar{d}} \\
\text { के }\end{array}$ & \begin{tabular}{|l|} 
\\
ఫे \\
స్త
\end{tabular} & 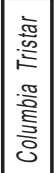 & 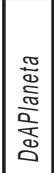 & $\stackrel{\varrho}{5}$ & 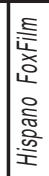 & 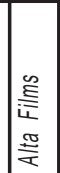 & $\frac{\mathrm{a}}{\overline{5}}$ & $\frac{E}{\frac{E}{O}}$ & 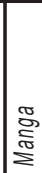 \\
\hline $\begin{array}{l}\text { 恿 } \\
\text { 出 }\end{array}$ & 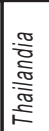 & 灾 & 空 & 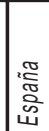 & 岃 & 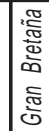 & 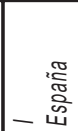 & 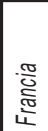 & 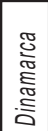 & 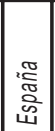 & 蛋 & $\underset{\text { 出 }}{\grave{3}}$ & 恿 & 蛋 & 恿 & 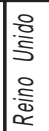 & 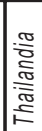 \\
\hline 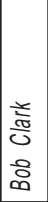 & 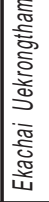 & 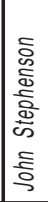 & 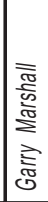 & 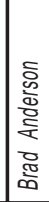 & 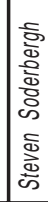 & 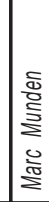 & 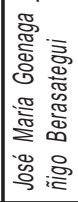 & 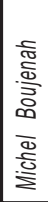 & 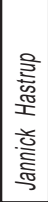 & 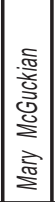 & 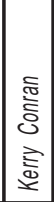 & 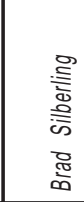 & 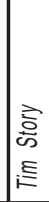 & 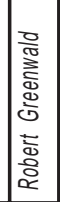 & 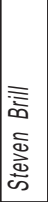 & 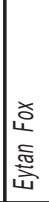 & 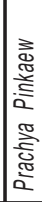 \\
\hline 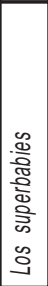 & 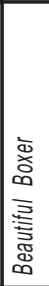 & 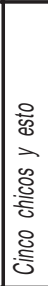 & 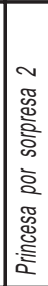 & 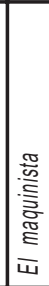 & 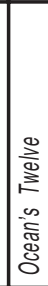 & 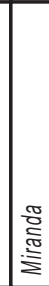 & 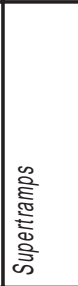 & 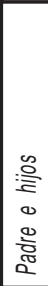 & 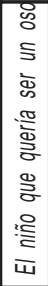 & 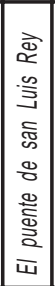 & 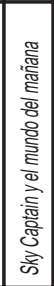 & 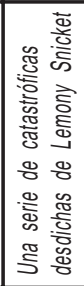 & 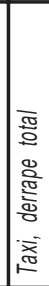 & 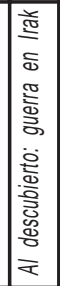 & 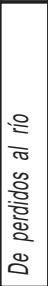 & 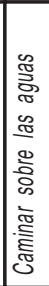 & 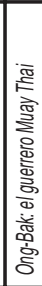 \\
\hline 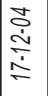 & $\begin{array}{l}\frac{0}{\dot{1}} \\
\frac{\tilde{1}}{=}\end{array}$ & 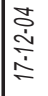 & 竞 & 辛 & & 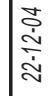 & 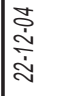 & 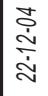 & $\begin{array}{l}\text { d̦ } \\
\text { ते } \\
\text { ते }\end{array}$ & 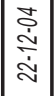 & 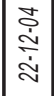 & 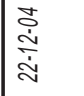 & 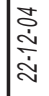 & 离 & $\frac{\text { वे. }}{\text { ஸें }}$ & 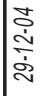 & $\frac{\text { वे }}{\text { ণे }}$ \\
\hline
\end{tabular}




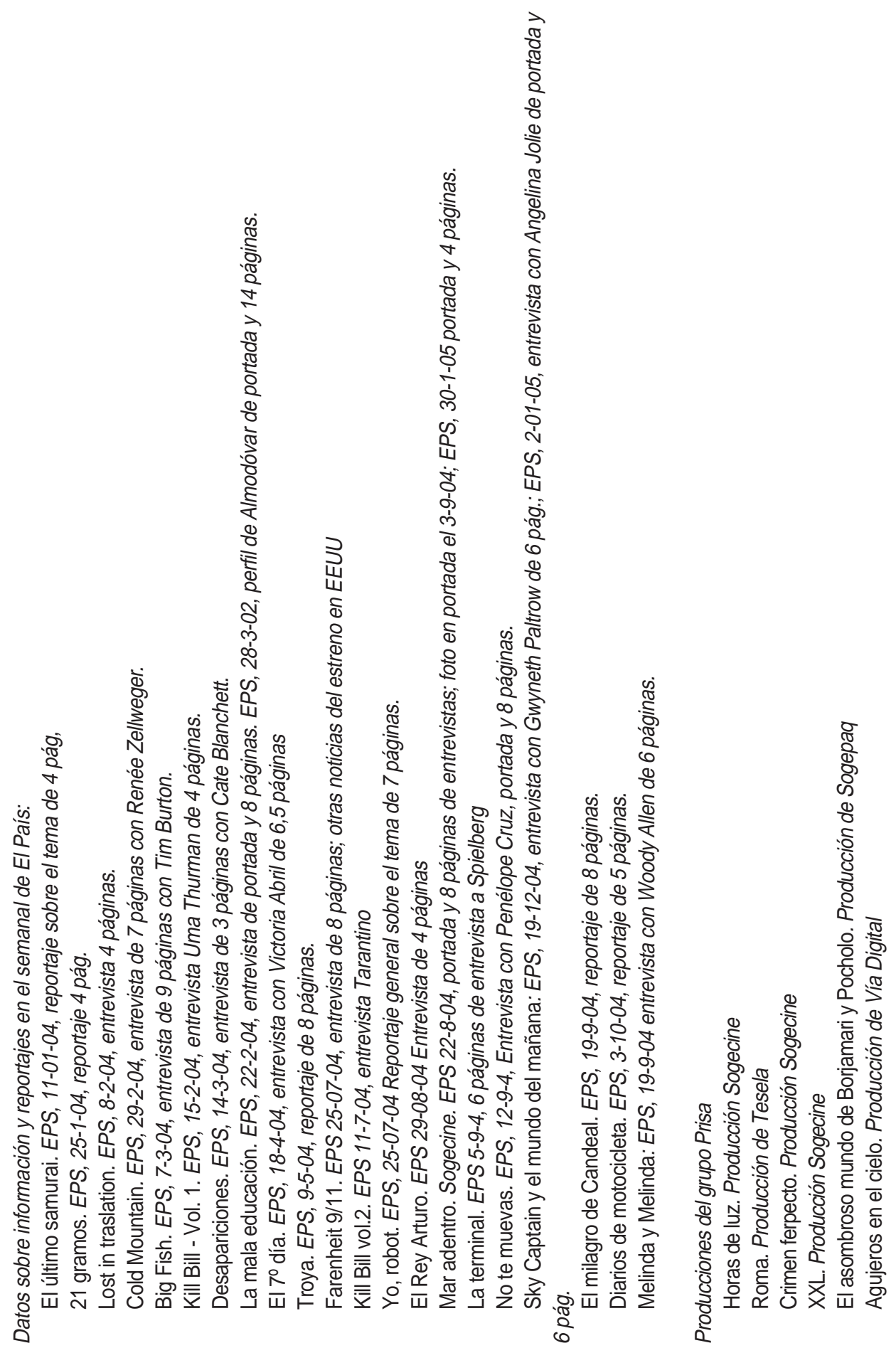

